NASA/TP-2003-212285

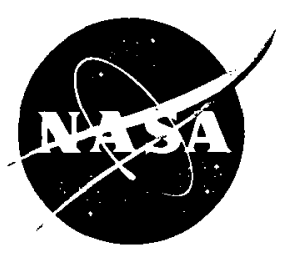

\title{
Magnetohydrodynamic Augmented Propulsion Experiment: I. Performance Analysis and Design
}

R.J. Litchford and J.W. Cole

Marshall Space Flight Center, Marshall Space Flight Center, Alabama

J.T Lineberry, J.N. Chapman, H.J. Schmidt, and C.W. Lineberry LyTec LLC, Tullahoma, Tennessee

National Aeronautics and

Space Administration

Marshall Space Flight Center • MSFC, Alabama 35812 


\section{Acknowledgments}

This work was sponsored by the Space Transportation Research Project Office, Advanced Space Transportation Program, George C. Marshall Space Flight Center, National Aeronautics and Space Administration. The NASA Principal Investigator was Ron J. Litchford, Project Scientist, Space Transportation Research Project Office, TD15/ASTP.

Available from:

NASA Center for AeroSpace Information 7121 Standard Drive

Hanover, MD 21076-1320

(301) 621-0390
National Technical Information Service 5285 Port Royal Road Springfield, VA 22161 (703) 487-4650 


\section{TABLE OF CONTENTS}

1. INTRODUCTION

2. HISTORICAL PERSPECTIVE _.......................................................................................... 3

2.1 NASA Langley Research Center Program .......................................................................... 3

2.2 United States Air Force Arnold Engineering Development Center Programs ........................ 4

2.2.1 LORHO (Low-Density Focus) Program ....................................................................... 4

2.2.2 HIRHO (High-Density Focus) Program ……….......................................................... 5

2.3 Aerospace Corporation and General Electric Programs ........................................................ 5

2.4 Russian Central Institute of Aerohydrodynamics (TsAGI) Program ........................................ 5

2.5 Research and Technology Legacy ............................................................................. 6

3. MAGNETOHYDRODYNAMIC AUGMENTED PROPULSION EXPERIMENT

FLOW-PATH ANALYSIS AND DESIGN ............................................................................ 7

3.1 Hot Gas Source and Entrance Flow Path ............................................................................... 7

3.2 Magnetohydrodynamic Accelerator Channel ………............................................................. 9

3.2.1 Electrical Loading Configuration .................................................................................. 9

3.2.2 Performance Theory …………………………........................................................ 9

3.2.3 Electrodynamics of Diagonally Shorted Channel ........................................................ 10

3.2.4 Performance Analysis and Flow-Path Design ........................................................ 12

3.2.5 Engineering Design ........................................................................................... 14

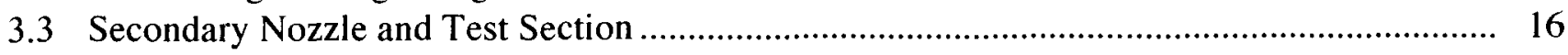

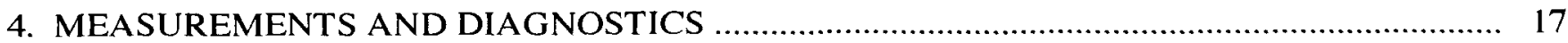

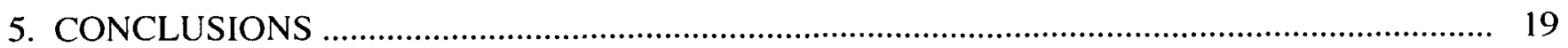

REFERENCES _... 


\section{LIST OF FIGURES}

1. Schematic of NASA MSFC's MAPX facility. The major flow-path components are: (1) 1.5- $\mathrm{MW}_{\mathrm{e}}$ Aerotherm arc heater, (2) seed injector and mixing chamber, (3) primary expansion nozzle, (4) 2-MW $\mathrm{MW}_{\mathrm{e}} \mathrm{MHD}$ accelerator channel and 2-T electromagnet, (5) secondary nozzle, (6) windowed test section, and (7) $\mathrm{N}$-driven ejector pump

2. Photographs of the $1.5-\mathrm{MW}_{\mathrm{e}}$ Aerotherm arc heater in preparation for shakedown testing

3. Exploded schematic of entrance flow-path assembly for MAPX. The major pieces include (1) the ceramic isolation flange, which electrically isolates the MHD accelerator from the arc heater and provides a circular-to-square cross-section transition; (2) the water-cooled seed-injector flange and mixer assembly; and (3) the water-cooled primary nozzle assembly

4. Alternative MHD accelerator configurations

5. Illustration of diagonal linkage and the resulting field vector orientations

6. Performance diagram for Hall current neutralized accelerator

7. Predicted distributions of gas-dynamic and electrical properties along the channel of the MAPX accelerator for the Hall current neutralized condition. All parameters are normalized by their value at the inlet

8. Cross section of heat-sink accelerator channel illustrating construction detail

9. Schematic of fully assembled MAPX accelerator channel positioned inside the magnet bore

10. Schematic of microwave interferometer. It simultaneously probes at 70, 90, and $110 \mathrm{GHz}$ and may be operated in reflectometer mode

11. PLIF velocity/temperature diagnostic 


\section{LIST OF TABLES}

1. Arc heater performance estimates (air) ………............................................................. 8

2. Primary nozzle performance (air/1 percent $\mathrm{NaK}$ ) ….......................................................... 9

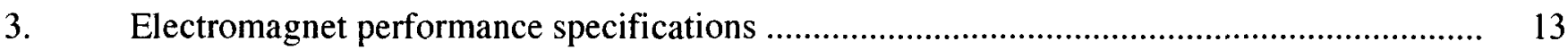

4. MAPX accelerator physical specifications …................................................................. 13

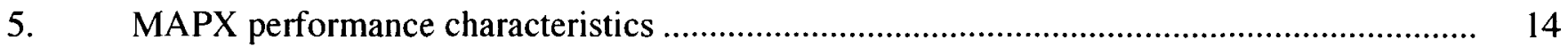


A cross-sectional area

$A^{*} \quad$ throat area

$A_{f} \quad$ slanted area enclosed by a diagonal link

$B \quad$ magnetic field strength (induction)

B magnetic field strength vector

E electric field

E electric field vector

$\mathbf{E}_{d} \quad$ electric field of boundary layer voltage drop

$\mathrm{E}_{x} \quad$ axial electric field

$\mathrm{E}_{y} \quad$ transverse electric field

G Rosa G factor

$h \quad$ channel height

I current

$j \quad$ current density

j current density vector

$k \quad$ load factor

$M \quad$ Mach number

$N \quad$ number of electrodes

$N_{p} \quad$ number of powered electrodes

$n \quad$ power law distribution parameter

n unit vector normal to slanted area $\mathrm{A}_{f}$

$P \quad$ static pressure

$P_{0} \quad$ total pressure

$Q_{t h} \quad$ thermal power

$T$ temperature

$T_{0} \quad$ total temperature

$u \quad$ axial flow velocity

u velocity vector

V voltage

$V_{d} \quad$ effective voltage drop 


\section{LIST OF ACRONYMS AND SYMBOLS}

\begin{tabular}{ll} 
AEDC & Arnold Engineering Development Center \\
BN & boron nitride \\
Cu & copper \\
Cs & cesium \\
DCW & diagonal conducting wall \\
HIRHO & high-density focus program \\
ICCD & intensified charged-coupled device \\
K & potassium \\
LORHO & low-density focus program \\
MAPX & Magnetohydrodynamic Augmented Propulsion Experiment \\
MHD & magnetohydrodynamic \\
MSFC & Marshall Space Flight Center \\
N & nitrogen \\
NaK & liquid metal \\
ND:YAG & neodymium: yttrium aluminum garnet \\
PLIF & planar laser-induced fluorescence \\
Rb & rubidium \\
TsAGI & Central Institute of Aerohydrodynamics \\
USAF & United States Air Force \\
& \\
\hline
\end{tabular}




\section{NOMENCLATURE (Continued)}

$\begin{array}{ll}W_{e} & \text { electric power } \\ x & \text { axis } \\ y & \text { axis } \\ z & \text { axis } \\ \beta & \text { Hall parameter } \\ \gamma & \text { specific heat ratio } \\ \Delta & \text { dimensionless effective voltage drop } \\ \eta & \text { accelerator efficiency } \\ \varphi & \text { electric field direction (tan } \theta) \\ \sigma & \text { electrical conductivity } \\ \theta & \text { diagonalization angle } \\ \theta_{w} & \text { wall angle }\end{array}$




\section{TECHNICAL PUBLICATION}

\section{MAGNETOHYDRODYNAMIC AUGMENTED PROPULSION EXPERIMENT: PERFORMANCE ANALYSIS AND DESIGN}

\section{INTRODUCTION}

In general, thermal propulsion systems exhibit attributes of very high power but low specific energy. The attribute of high power derives from exceptionally good chemical-to-thermal-to-kinetic energy conversion efficiency (>98 percent) and ready scalability to high mass flow rates; i.e., high jet power. On the other hand, the attribute of low specific energy derives from the limited energy content of available chemical fuels $(\approx 10 \mathrm{MJ} / \mathrm{kg}$ for liquid oxygen/hydrogen). Moreover, even if a super high-energy-density fuel could be synthesized at production scales, the thermal limits of existing materials would prevent its full utilization as a propellant.

Consequently, the performance of conventional thermal propulsion systems is fundamentally constrained by the specific energy limitations associated with chemical fuels and the thermal limits of available materials. For many in-space missions, where power is limited and low vehicle acceleration; i.e., milli-g, is acceptable, these limitations can be successfully circumvented through the utilization of high specific impulse electric thrusters coupled to onboard electrical power plants. There are, however, certain space transportation applications, such as Earth orbit access and rapid orbital plane changes, where achieving adequate thrust; i.e., vehicle acceleration, is an essential factor, and thermal propulsion systems producing high jet power are the only viable solution.

For these space transportation applications requiring high vehicle accelerations, it is only natural to consider electrical augmentation of thermal propulsion systems as a plausible means of increasing exhaust velocity, and possibly improving their specific energy attributes. In this way, one might hope to reduce the fuel fraction and shrink vehicle size without sacrificing payload delivery capability. Such considerations lead to some extremely daunting technical challenges, however.

To obtain a meaningful improvement in fuel fraction, for instance, it can be shown that the electrical augmentation power must be greater in magnitude than the thermal power of the unaugmented source. This conclusion raises a host of difficult questions: Is it possible to construct an onboard electrical power source having sufficient specific power to reduce fuel fraction without simultaneously reducing payload delivery capability? Is it more effective to beam energy to the vehicle and perform onboard power conversion for thrust augmentation? Can high mass flow rate exhaust jets expelled by thermal devices be effectively accelerated using electromagnetic techniques?

Currently, the required energy storage and power conversion technologies do not exist. There are, however, some promising avenues that may ultimately lead to new compact high-power energy sources. 
For example, research on high strength-to-weight nanomaterials (e.g., carbon nanotubes) represents one possibility by which super high-energy-density storage devices (e.g., flywheels and superconduction magnetic energy storage) might be obtained in the future. Advanced closed-cycle nuclear power plants may also be an option if an adequate heat sink is available for removing the waste heat. Rapid progress in high-power beamed energy technology represents an additional possibility for meeting the fundamental power source requirements.

Fortunately, questions regarding the feasibility of electromagnetic acceleration are less problematic and more amenable to research investigations. There is, in fact, a substantial legacy of plasma acceleration research from which to embark on a serious research and technology development program.

The essential requirement for using electromagnetic acceleration techniques is that the exhaust jet from the thermal propulsion source be electrically conductive. In practice, this can be accomplished by seeding the combustor flow of a chemical rocket with an alkali metal vapor, such as cesium (Cs), rubidium $(\mathrm{Rb})$, potassium $(\mathrm{K})$, and associated compounds. Because alkali metals have a relatively low ionization potential, the energy consumed in fully ionizing the seed is only a small fraction of the available thermal energy. Furthermore, the relatively low plasma working temperature is compatible with existing materials and regenerative cooling techniques. Using energetic rocket fuels, this method is known to produce supersonic plasma flows with an electrical conductivity on the order of $10^{2} \mathrm{~S} / \mathrm{m}$, which is sufficient for evoking significant magnetohydrodynamic (MHD) interaction.

At this level of MHD interaction, steady plasma acceleration is best invoked through externally imposed crossed electric and magnetic fields. This configuration gives rise to the so-called "cross-field MHD accelerator" in which the imposed Lorentz body force accelerates the flow.

Small prototypes for this class of plasma accelerator have been designed and built, but almost exclusively from the standpoint of producing a hypersonic wind tunnel rather than a propulsive device. Testing with these prototype devices has clearly demonstrated flow acceleration, but diagnostic limitations have prevented complete delineation of the fundamental physical phenomena. Many uncertainties remain including the relative importance of electromagnetic versus electrothermal effects, achievable accelerator efficiencies, achievable current densities, maximum sustainable axial electric field without interelectrode arcing, effect of near-wall, velocity-overshoot phenomena, effect of microarcing in the cold electrode boundary layer, multiterminal loading of a segmented Faraday channel versus two-terminal loading of a diagonal wall configuration, and thermal loading and erosive effects with respect to long-term channel survivability, to name a few.

This Technical Publication describes the design and development of the Magnetohydrodynamic Augmented Propulsion Experiment (MAPX), which is being undertaken by NASA Marshall Space Flight Center (MSFC) to resolve critical research issues associated with the use of MHD accelerators as thrust augmentation devices. In this experiment, a 1.5-MW $\mathrm{MW}_{\mathrm{e}}$ Aerotherm arc heater will be used to drive a $2-\mathrm{MW}_{\mathrm{e}}$ MHD accelerator. The heat-sink MHD accelerator is configured as an externally diagonalized segmented channel, which is inserted into a large-bore, 2-T electromagnet. The performance analysis and engineering design of the flow path are described as well as the parameter measurements and flow diagnostics planned for the initial series of test runs. 


\section{HISTORICAL PERSPECTIVE}

Cross-field MHD accelerator development has a long and checkered history, and it is useful to review its historical origins as well as the major research and technology programs over the years. These origins can be traced to the close of the 1950s, when it was suggested that plasma acceleration by Lorentz (i.e., $\mathbf{j} \times \mathbf{B}$ ) forces could be effectively used for propulsive effects, and subsequent research efforts examined its feasibility for both equilibrium and nonequilibrium ionization conditions. ${ }^{1-7}$ Interest in the propulsive application waned, however, as other electric thruster technologies ascended in importance and began to mature.

During a similar time period, the advent of manned space flight programs as well as military needs created a demand for steady flow aerodynamic test facilities capable of simulating a broad range of hypersonic flight conditions. It also became evident that a conventional approach using arc heater sources would not be feasible since the achievable arc stagnation pressure was far below the level required for complete simulation of relevant hypersonic flow conditions. The required stagnation conditions precluded a purely thermal approach, in any case, since this would lead to disintegration of the nozzle throat within a matter of milliseconds.

Around this time, Ring, ${ }^{8}$ at the United States Air Force (USAF) Arnold Engineering Development Center (AEDC), and Wood et al., ${ }^{9}$ at the NASA Langley Research Center, independently recognized that MHD acceleration of an arc heater exhaust stream is an effective nonthermal means for adding energy and momentum to the flow, thereby achieving a drastic increase in stagnation pressure. Moreover, Ring's study clearly indicated that seeded air could be accelerated to hypervelocities at densities relevant to hypersonic flight.

Since that initial revelation, a number of MHD accelerator programs have been initiated from time to time, both in the United States and abroad, with the ultimate goal of developing a true hypersonic wind tunnel capability. Since the fundamental problems for the cross-field MHD accelerator are the same, irrespective of the application, hypersonic wind tunnel or propulsion, the results obtained from these studies are of mutual value and interest. A summary of the major legacy programs follows.

\subsection{NASA Langley Research Center Program}

NASA Langley pioneered the development of MHD accelerators and sustained a productive research program for more than a decade. Their dual objectives throughout this period was the development of a hypersonic wind tunnel for investigating planetary reentry and the accumulation of results applicable to space propulsion. All of their reported experiments utilized Cs-seeded nitrogen $(\mathrm{N})$ as the working medium.

Their initial research was concentrated on small-scale, proof-of-principle experiments, which allowed the group to gain valuable experience and to work out some of the basic engineering design problems on an amenable scale. The first accelerator, for example, was a $1-\mathrm{cm}$-square by $8.7-\mathrm{cm}$-long segmented Faraday 
channel with seven electrode pairs. ${ }^{10,11}$ This device provided the first positive evidence of high-density plasma acceleration, and performance was steadily improved until they were able to achieve a 100-percent increase in stagnation pressure $(\approx 50$-percent increase in velocity) with an applied current of $115 \mathrm{~A}$ and a magnetic field of $1.1 \mathrm{~T}$.

The group's first channel was too small for implementation of diagnostics, and a second larger accelerator was designed and constructed to serve as a pilot model for a practical scale device. ${ }^{12.13}$ The second channel was $2.54 \mathrm{~cm}$ square by $30 \mathrm{~cm}$ long with 24 electrode pairs. This device performed extremely well, yielding a three-fold increase in velocity $(2-6 \mathrm{~km} / \mathrm{s})$ with an applied magnetic field of $1.15 \mathrm{~T}$ and an accelerator input power of $\approx 360 \mathrm{~kW}_{\mathrm{e}}$.

The Langley group's third and final accelerator was a 20-MW facility based on a 6.35-cm-square by 50 -cm-long segmented Faraday channel with 36 electrode pairs. ${ }^{14,15}$ Experience with this device, which was designed to produce an exit velocity of $13 \mathrm{~km} / \mathrm{s}$ at a density corresponding to an altitude of $53 \mathrm{~km}$, was limited to a few preliminary tests prior to cancellation of the research program. These tests, in which only 30 of the 36 electrodes were powered, demonstrated a two-and-one-half-fold increase in velocity, yielding an exit velocity of $9.6 \mathrm{~km} / \mathrm{s}$.

In retrospect, the NASA Langley program was an extremely successful effort, demonstrating the productive character of a long-term sustained research strategy. The legacy of analysis, engineering, and technology from this program is of continuing interest and value to contemporary efforts.

\subsection{United States Air Force Arnold Engineering Development Center Programs}

The USAF implemented two parallel MHD accelerator programs at AEDC during the 1960s to meet its own hypersonic testing needs: the low-density focus (LORHO) and high-density focus (HIRHO) programs. $^{16}$

\subsubsection{LORHO (Low-Density Focus) Program}

The LORHO program was formulated as a long-term technology development plan beginning with small-scale, proof-of-principle experiments, advancing to a pilot-scale facility, and ending with a fullscale, steady-flow hypersonic test facility.

The proof-of-principle experiments, concentrating mainly on K-seeded air, resulted in the construction and testing of three different accelerator configurations using a 1.2-MW arc heater and a 2-T magnetic field. ${ }^{17,18}$ The first accelerator was a 20-electrode pair Faraday channel which achieved a velocity increase of $\approx 50$ percent ( $3-\mathrm{km} / \mathrm{s}$ exit velocity). Subsequent configurations used 117 -electrode pair channels and demonstrated a 100 -percent increase in velocity $(3.9-\mathrm{km} / \mathrm{s}$ exit velocity).

The follow-on 20-MW pilot-scale facility was designed as a matched MHD generator/accelerator system. 19,20 The rocket-driven MHD Hall generator was successfully fired with toluene producing $18 \mathrm{MW}$ of electrical power (90 percent of design value). A two-terminal diagonal conducting wall (DCW) MHD accelerator was designed and built; unfortunately, it was never tested. Brogan, a principal architect in the design, recently published an excellent summary and critique of this innovative accelerator. ${ }^{20}$ The design 
principles and experience derived for the LORHO DCW accelerator are of special interest and importance to the MAPX program, which is also based on a two-terminal diagonalized channel. The LORHO program essentially ended with the cancellation of the pilot-scale facility.

\subsubsection{HIRHO (High-Density Focus) Program}

The HIRHO program was formulated to address the high-density hypersonic flight regimes of interest to the USAF. Like LORHO, it was envisioned as a three-phase program progressing from proof-ofconcept, through pilot-scale demonstration, to full-scale test facility.

The proof-of-principle experiments were implemented through MHD augmentation of the AEDCVKF tunnel J shock-tube facility. ${ }^{21}$ A nozzle and 46-cm-long diverging segmented Faraday channel with 11 electrode pairs were connected to the shock tube and operated in reflected shock mode. Using K-seeded air as the driven gas, it was possible to demonstrate an 80-percent increase in velocity with a 7.5-T applied field and 0.25 MJ of energy discharged into the accelerator. More importantly, these experiments demonstrated an electric-to-kinetic conversion efficiency of better than 85 percent. Unfortunately, the very successful HIRHO program was terminated at this stage as interest in hypersonic flight applications declined.

\subsection{Aerospace Corporation and General Electric Programs}

The Aerospace Corporation conducted pulsed experiments using a hot-shot plasma generator. ${ }^{22}$ Their diverging segmented Faraday channel was $76 \mathrm{~cm}$ long with 94 electrode pairs. Tests with this device using $\mathrm{N}$ seeded with $\mathrm{K}$ azide and a 4-T magnetic field yielded a 50-percent increase in exit velocity $(7.3 \mathrm{~km} / \mathrm{s})$.

The General Electric Company conducted an additional pulsed MHD accelerator experiment using an electrically-driven reflected shock tunnel. ${ }^{23}$ This experiment was novel in that the unseeded air was used as the working fluid. Their diverging segmented Faraday channel was $31 \mathrm{~cm}$ long with 38 electrode pairs. Tests with this device using a 5-T magnetic field were reported to have achieved a 22-percent increase in velocity with an electrical-to-kinetic energy conversion of $\approx 70$ percent.

\subsection{Russian Central Institute of Aerohydrodynamics (TsAGI) Program}

The only other major MHD accelerator development program outside of the United States was the Russian effort at the Central Institute of Aerohydrodynamics (TsAGI) led by Professor V.I. Alferov. ${ }^{24} \mathrm{This}$ effort, initiated during the Soviet era, was sustained for many years and resulted in a small-scale operational facility. This 1-MW facility is too small for practical aerodynamic testing and, like its counterparts in the United States, was intended primarily for proof-of-principle testing and fundamental research on hypersonic flows. The TsAGI facility has remained intact and, to the authors' knowledge, is the only operational steady-flow MHD accelerator in the world today.

The TsAGI facility is driven by a coaxial arc heater $(200-300 \mathrm{~kW})$ in which air is heated to $T_{0} \approx 3,700$ $\mathrm{K}$ at $P_{0} \approx 3 \mathrm{~atm}$. Seeding is accomplished by injecting liquid metal $(\mathrm{NaK})$ into a mixing chamber upstream from the primary nozzle. The 0.5 -m-long accelerator $\left(2.5-\mathrm{cm} \times 1.15-\mathrm{cm}\right.$ inlet area with $\approx 1^{\circ}$ expansion angle) is configured as a segmented Faraday channel with 80 independently powered electrodes and is 
inserted into a 2.5-T electromagnet. The accelerator attaches to a secondary nozzle and test section for investigating hypersonic flow.

Because the facility uses a heat-sink design, powered test times are limited to $1 \mathrm{~s}$, which is effectively steady state from the standpoint of flow dynamics. This facility has been utilized for many years, routinely achieving accelerator exit velocities around $6.5 \mathrm{~km} / \mathrm{s}$ and nozzle exhaust velocities approaching $9 \mathrm{~km} / \mathrm{s}$.

\subsection{Research and Technology Legacy}

Together, these major research and technology programs bequeath an immense wealth of knowledge and experience with respect to MHD accelerator design and operation. In proceeding with the design of a new facility, 50 years after inception of the basic concepts, the authors are indebted to these seminal efforts in the field and are striving to draw upon and incorporate this rich legacy of wisdom. 


\section{MAGNETOHYDRODYNAMIC AUGMENTED PROPULSION EXPERIMENT FLOW-PATH ANALYSIS AND DESIGN}

The NASA MSFC MAPX facility follows the traditional flow-path configuration established by previous investigators, as shown schematically in figure 1 . First, the working fluid (air, $\mathrm{N}$, etc.) is heated in a $1.5-\mathrm{MW}_{\mathrm{e}}$ Aerotherm arc heater to a stagnation temperature of $T_{0} \approx 4,000-4,500 \mathrm{~K}$ at a stagnation pressure $P_{0} \leq 10 \mathrm{~atm}$. The hot gas then enters a mixing chamber where it is seeded with alkali metals; e.g., NaK, and expanded through a primary nozzle to a Mach number, $M \approx 1.25-1.5$. A $2-\mathrm{MW}_{\mathrm{e}} \mathrm{MHD}$ accelerator directly increases the energy and momentum of the flow, which is further diffused in a secondary nozzle to obtain the maximum possible jet velocity. The secondary nozzle exhausts into a large-windowed test section equipped with a stinger mount and access for optical-based flow diagnostics. The test section is attached to an $\mathrm{N}$-driven ejector pump designed to maintain a backpressure less than $0.05 \mathrm{~atm}$.

The design and performance analysis of each major flow-path component is discussed below.

\subsection{Hot Gas Source and Entrance Flow Path}

The thermal driver for MAPX is a $1.5-\mathrm{MW}_{\mathrm{e}}$ Aerotherm arc heater acquired by NASA MSFC principally to support materials testing and certification. Its design follows a conventional approach with an axial arc established between a fixed tungsten cathode button at the upstream end and a ring anode on the downstream end. The ring anode is also equipped with a magnetic spin coil for continuous rotation of the arc attachment point. The main body consists of water-cooled copper $(\mathrm{Cu})$ segments separated by boron nitride (BN) insulators, and the segments are assembled in packs, which the user can stack according to their needs. The arc heater and matching power supply have been delivered to MSFC and are currently being assembled (three-pack configuration) and readied for initial shakedown testing, as shown in the photographs in figure 2 .

The purpose of the thermal driver is to obtain the highest possible mass throughput as a means of maximizing the accelerator channel size and thereby maximizing MHD interaction. This particular arc heater had seen considerable usage as Aerotherm's inhouse research unit, and a large body of empirical performance data had been accumulated and cataloged. Therefore, it was possible to make reliable estimates for arc heater performance and, because the entrance flow path is expected to be in thermodynamic equilibrium, to accurately predict the input conditions to the MHD accelerator.

Preliminary analysis, assuming fully powered operation and a 20 -percent heat loss in the mixing chamber and primary nozzle, indicated suitable accelerator entrance conditions could be obtained with $130 \mathrm{~g} / \mathrm{s}$ of air flowing through a 0.64 -in-diameter throat at the rated working pressure of $10 \mathrm{~atm}$. The projected arc heater performance for a three-pack configuration ( 27 in long) is summarized in table 1 for a fixed $130 \mathrm{~g} / \mathrm{s}$ flow rate of air at the rated working pressure. Note that the projected conversion efficiency exceeds 60 percent at all power levels. 
Table 1. Arc heater performance estimates (air).

\begin{tabular}{ccccc}
\hline $\boldsymbol{I}$ (amps) & $\boldsymbol{V}$ (volts) & $\mathbf{W}_{\mathbf{e}}$ (MW $\left._{\mathbf{e}}\right)$ & $\eta(\%)$ & $\boldsymbol{a}_{\mathbf{t h}}$ (MW) \\
\hline 200 & 3,480 & 0.70 & 80 & 0.56 \\
300 & 3,320 & 1.00 & 74 & 0.74 \\
400 & 3,210 & 1.28 & 70 & 0.90 \\
500 & 3,120 & 1.56 & 67 & 1.00 \\
600 & 3,060 & 1.84 & 64 & 1.20 \\
\hline
\end{tabular}

Ideally, both the ionizing seed material and primary working fluid would be mixed and heated within the thermal source. This is not feasible with an arc heater as it would dramatically reduce plasma resistivity, repress Joule heating, and result in severe discharge instabilities. Therefore, the best alternative is to directly inject the seed material as a pure alkali metal vapor just downstream of the arc heater and allow sufficient time for mixing upstream of the accelerating nozzle.

This particular approach was previously perfected by the NASA Langley group by electrically heating and vaporizing $\mathrm{Cs}$ in a small tube and injecting the pure vapor into the postdischarge region of the arc heater. This was a major engineering feat that required considerable skill and persistent effort. Although the long-term intent is to duplicate this capability for MAPX, the NaK aerosol injection scheme developed by the TsAGI group will be adapted initially.

Because $\mathrm{NaK}$ eutectic is a liquid metal under ambient conditions, the thermal management and injection system are greatly simplified. However, the material also introduces some major hazards and performance drawbacks. For example, $\mathrm{NaK}$ reacts violently upon contact with air, resulting in the formation of oxides that could clog the flow path. This possibility necessitates the use of an inert purge gas before and after injection. Careful attention must be given to the injection location to achieve efficient mixing and to preclude the penetration of the seed into the discharge region. For complete vaporization of metal aerosols, this typically requires a mixing chamber having a residence time of $1-10 \mathrm{~ms}$. Furthermore, the NaK should be exceptionally pure ( $\geq 99.99$ percent) to ensure optimal performance (V.I. Alferov, TsAGI, Moscow, Russia, Private Communications, 2001).

The primary nozzle flow was analyzed using a modified version of the NASA SP-273 chemical equilibrium code ${ }^{25}$ in which plasma electrical transport properties are computed, according to Frost. ${ }^{26}$ The results for air with 1-percent $\mathrm{NaK}$ are summarized in table 2 . In this case, the area expansion ratio is $A / A^{*}=1.17$. The flow could not be expanded further without severely reducing the static temperature and the electrical conductivity at the entrance to the MHD channel.

An exploded schematic of the entrance flow-path assembly is shown in figure 3 . This assembly accomplishes the following major functions: (1) Electrical isolation of the arc heater from the MHD accelerator and circular-to-square flow-path transition, (2) seed injection and mixing, and (3) accelerating nozzle. The ceramic isolator is designed for heat-sink operation and is an expendable item, while the other components are all water-cooled Cu pieces intended for indefinite service. The engineering drawings for these assemblies have been completed, reviewed, and released to CoorsTec (Coors Ceramic Company, Golden, $\mathrm{CO}$ ) for fabrication. 
Table 2. Primary nozzle performance (air/1 percent $\mathrm{NaK}$ ).

\begin{tabular}{lccc}
\hline & $\begin{array}{c}\text { Mixing } \\
\text { Chamber }\end{array}$ & $\begin{array}{c}\text { Nozzle } \\
\text { Throat }\end{array}$ & $\begin{array}{c}\text { Accelerator } \\
\text { Entrance }\end{array}$ \\
\hline$P(\mathrm{~atm})$ & 10 & 6.6 & 3.2 \\
$T(\mathrm{~K})$ & 4,300 & 4,000 & 2,700 \\
$\gamma$ & 1.198 & 1.186 & 1.213 \\
$U(\mathrm{~m} / \mathrm{s})$ & - & 1,210 & 1,300 \\
$M$ & - & 1 & 1.35 \\
$\sigma(\mathrm{S} / \mathrm{m})$ & 325 & 274 & 40 \\
\hline
\end{tabular}

\subsection{Magnetohydrodynamic Accelerator Channel}

\subsubsection{Electrical Loading Configuration}

The optimal MHD accelerator configuration is determined by the ultimate application needs. From a performance standpoint, the Hall configuration (fig. 4(a)) is more effective for low-density flows whereas the Faraday configuration (fig. 4(b)), with segmentation to neutralize the Hall current, is superior for highdensity flows. ${ }^{8}$ The major drawback of the Faraday configuration, however, is the separate power conditioning required for each electrode pair which leads to a complex and expensive system. In many cases, particularly flight applications, multiterminal loading is not practical.

Alternative two-terminal loading schemes have been proposed to avoid the multiterminal complications while attempting to reap the major benefit associated with the Faraday configuration; i.e., Hall current neutralization. De Montardy, for example, suggested the series-connected scheme in which a segmented Faraday channel is externally diagonalized (fig. 4(c)). ${ }^{27}$ Later, Dicks proposed the DCW configuration in which slanted window frame-like electrode elements are stacked with thin insulators to form a complete channel (fig. 4(d)) ${ }^{28,29} \mathrm{The} \mathrm{DCW}$ configuration not only simplifies fabrication and improves strength but provides superior performance to the externally shorted; i.e., series-connected, device by allowing current to flow to the sidewalls. ${ }^{30}$

Ultimately, it is the authors' belief that the DCW configuration is the best candidate for flight implementation; however, for reasons of cost and flexibility (e.g., effective wall-angle adjustability), MAPX is based on an externally diagonalized series-connected configuration.

\subsubsection{Performance Theory}

Numerous investigations have clearly established that MHD channel flows are subject to significant three-dimensional effects. Thus, averaging the governing MHD equations (magnetic Reynolds number «1) to obtain a quasi-one-dimensional engineering model requires the adoption of major simplifying assumptions. Nevertheless, many of these assumptions, including wall friction, wall-heat flux, and near-electrode voltage drops, can be accounted for through the introduction of appropriate physical submodels for the boundary layer. 
Performance analysis of the MAPX accelerator was carried out using a legacy code based on one such approach. This engineering code was initially developed within the Energy Conversion Division at The University of Tennessee Space Institute in support of the Department of Energy MHD Commercial Power Program. Over the years, the code was evolved and expanded to encompass a range of generator and accelerator loading configurations. In most respects, the development is similar to that described for other nonperfect-gas quasi-one-dimensional analyses, the principal idiosyncrasies being associated with the physical submodeling. ${ }^{15}$

The code solves the governing internal duct flow equations for conservation of mass, momentum, and energy together with the equation of state using a fourth-order Runge-Kutta numerical integration scheme. It uses a real-gas equation of state and assumes local thermodynamic equilibrium as predicted by the NASA SP-273 code with modifications for computing electrical transport properties according to the Frost mixing model. ${ }^{26}$

\subsubsection{Electrodynamics of Diagonally Shorted Channel}

Diagonal shorting of the accelerator introduces some novel considerations and should be discussed in some detail. The defining constraint for this family of devices is the condition

$$
\frac{E_{y}}{E_{x}}=\tan \theta=\varphi .
$$

That is, diagonal shorting causes the equipotential line to run parallel to the diagonalization angle and aligns the net electric field perpendicular to the diagonal link. The diagonal linkage and resulting field vector orientations are illustrated in figure 5 . The load current in the diagonal device is

$$
I=\mathbf{j} \times \mathbf{n} \mathrm{A}_{f}=\left(j_{x}+\varphi j_{y}\right) A,
$$

where $\mathrm{A}_{f}$ is the slanted area enclosed by a diagonal link and $\mathbf{n}$ is the direction of $\mathrm{A}_{f}$

In all cases, the current density and electric field intensity are related through the generalized Ohm's law neglecting ion mobility, diffusion, and electron inertia:

$$
\mathbf{j}=\sigma\left(\mathbf{E}+\mathbf{u} \times \mathbf{B}+\mathbf{E}_{d}\right)-(\beta / B)(\mathbf{j} \times \mathbf{B})
$$

where $\mathbf{E}_{d}=V_{d} / h$ is the electric field associated with the boundary layer voltage drop and $\beta$ is the Hall parameter.

Combining equations (1)-(3) yields a set of equations governing diagonally connected accelerator operation in terms of the applied current $I$ :

$$
j_{x}=\frac{(1-\beta \varphi) I+A \sigma u B(1+\Delta) \varphi}{A\left(1+\varphi^{2}\right)}
$$




$$
\begin{gathered}
j_{y}=\frac{(\varphi+\beta) I-A \sigma u B(1+\Delta)}{A\left(1+\varphi^{2}\right)}, \\
E_{x}=\frac{\left(1+\beta^{2}\right) I-A \sigma u B(1+\Delta)(\beta-\varphi)}{\sigma A\left(1+\varphi^{2}\right)},
\end{gathered}
$$

and

$$
E_{y}=\varphi E_{x},
$$

where $\Delta=V_{d} / u B h$ is Wu's dimensionless effective voltage drop. ${ }^{30}$

Setting $j_{x}=0$ in equation (4) yields the Hall current neutralized condition

$$
I=-A \sigma u B(1+\Delta) \varphi /(1-\beta \varphi)
$$

or

$$
\varphi=\frac{I}{\beta I-A \sigma u B(1+\Delta)} .
$$

Note that $j_{y}$ under a Hall current neutralized condition is determined directly from equations (2) and (8)

$$
j_{y}=\frac{I}{\varphi A}=-\frac{\sigma u B(1+\Delta)}{(1-\beta \varphi)}
$$

It is of interest to compare this result to that for a segmented Faraday channel, which is effectively Hall current neutralized. In this case

$$
j_{y}=\sigma u B(1+\Delta)(1-k)
$$

where $k=E / u B(1+\Delta)$ is the load factor. Combining equations (10) and (11) yields the electric field angle for which the current in a diagonalized accelerator is equivalent to that in a segmented Faraday device

$$
\varphi=\frac{k}{\beta(k-1)} .
$$

It is instructive to examine these consequences in terms of an MHD performance diagram as introduced by Powers et al. ${ }^{31}$ The resulting power diagram for the Hall current neutralized accelerator is shown in figure 6 on the plane of nondimensional current density (hat symbols denote normalized variables). 
The circles that comprise the diagram represent discrete nondimensional power densities with the solid circle representing the zero power condition; i.e., short circuit operation on the right side and open circuit operation on the left side. Circles inside the zero power demarcation represent various power generation modes whereas those outside represent externally powered devices. To obtain an acceleration mode, some portion of the applied power density circle must lie above the abscissa $\left(j_{y}>0\right)$.

Note that each location on the power circle is indicative of certain physical parameter values. The bottom intersection point of the zero-power circle with the $j_{y}$ axis, for instance, represents the condition where $\varphi$ and $\beta$ are both zero. Moving counterclockwise around the circle from this point corresponds to an increase in $\beta$. Moving clockwise around the circle from this point corresponds to an increase in $\varphi$; i.e., increase in diagonalization angle which is set by the designer.

To define the operating conditions for any particular device, a line is drawn from the point on the zero-power circle corresponding to a preset diagonalization angle through a second point on the zeropower circle corresponding to the effective Hall parameter. The line inside the zero-power circle corresponds to the loadline for power generation. Portions of the line outside the zero-power circle represent an externally powered condition.

Thus, for any given applied power circle of sufficient radius, the intersection of the power circle with the ordinate at a point above the abscissa defines the Hall current neutralized condition. An operating line from the fixed operating point through a point on the circle corresponding to the effective Hall parameter may then be drawn. The intersection of this line with the power circle defines the required diagonalization angle (negative value for accelerator). Several Hall current neutralized loadlines have been constructed in figure 6 to illustrate the dependence of $\varphi$ on $\beta$.

Irrespective of the analytical results, it should be noted that MHD generators/accelerators having diagonalization angles exceeding $\pm 45^{\circ}$ are mechanically difficult to construct and therefore impractical. Furthermore, the Hall parameter will vary considerably along the length of the device as the temperature and pressure change. Consequently, achieving Hall current neutralized operation everywhere locally requires variation of the diagonalization angle with length, which is plausible but difficult to achieve in practice due to finite-sized electrode segmentation.

\subsubsection{Performance Analysis and Flow-Path Design}

Analysis of the MAPX accelerator flow path was based on performance calculations carried out with the existing legacy engineering code. Values for the empirical constants associated with various physical submodels were established through extensive benchmarking experience.

Heat transfer and frictional wall losses are computed intrinsically in the code and require input of the wall temperature and roughness height. Near-wall electrical losses are also treated intrinsically through integration of the conductivity profile as defined by velocity and thermal boundary layer correlations for fully turbulent flow. This correlation computes the boundary layer growth along the MHD accelerator duct through definition/input of the initial boundary layer height and shear (viscosity as a function of temperature). The velocity and temperature profiles are taken as $1 / n$ power-law distributions. This approach relies on user specification of the Rosa $\mathrm{G}$ factor to account for plasma nonuniformities and effective voltage drop. ${ }^{32}$ A value of $G \approx 2$ is anticipated based on past experience. 
The cross-sectional area distribution of the accelerator duct is required input as well as the total mass flow rate, which is keyed to specification of the inlet thermodynamic state. The channel inlet conditions were obtained from the entrance flow-path analysis described previously.

Detailed design of any accelerator depends, of course, on the available magnet and power supply equipment. In this case, a water-cooled 2-T electromagnet was acquired from The University of Tennessee Space Institute and refurbished to support general MHD research at MSFC. The specifications for this magnet are summarized in table 3 . A new 3,000-A, $75-\mathrm{V}$ dc power supply was acquired to power the magnet, and the entire system is currently being integrated into the MAPX flow train.

Table 3. Electromagnet performance specifications.

\begin{tabular}{lr}
\hline Field strength (T) & 2 \\
Air gap (in) & 4 \\
Pole cap length (in) & 36 \\
Voltage (V) & 65 \\
Maximum current (amps) & 2,400 \\
Cooling water (gpm @ 70 psig) & 50 \\
\hline
\end{tabular}

Based on existing power availability and preliminary sizing calculations, it was concluded that $2-\mathrm{MW}_{\mathrm{e}}$ of accelerator power would be sufficient to meet the research goals of the program and still fit within the facility power budget as well as the program fiscal budget. Following some preliminary design calculations, it was possible to define the required characteristics of the high voltage dc power supply, and a suitable unit was requisitioned and purchased. The voltage on this unit is variable to $10 \mathrm{kV}$ with a nominal output of $6,700 \mathrm{~V}$ at a load current of $300 \mathrm{~A}$. The power supply and control unit have been delivered to MSFC and are currently being integrated into the MAPX flow train.

The detailed design process entailed several iterative calculations in an attempt to optimize stagnation pressure rise by varying load current, channel divergence, and channel length. These calculations were carried out assuming a uniform 2-T applied magnetic field at full magnet power. The height-to-width aspect ratio was one at the inlet, and the $\mathbf{E}$ - and $\mathbf{B}$-field walls were diverged to accommodate boundary layer growth and flow expansion. The resulting physical specifications for the accelerator are summarized in table 4.

Table 4. MAPX accelerator physical specifications.

\begin{tabular}{lc}
\hline Inlet height $\times$ width $\left(\mathrm{cm}^{2}\right)$ & $1.6 \times 1.6$ \\
Channel divergence $($ degrees $)$ & 1 \\
Electrode width $(\mathrm{cm})$ & 1 \\
Insulator width $(\mathrm{cm})$ & 0.5 \\
Active length $(\mathrm{cm})$ & 90 \\
Powered electrodes $\left(N_{\mathrm{p}}\right)$ & 60 \\
Total length $(\mathrm{cm})$ & 96 \\
Total electrodes $(M)$ & 65 \\
Exit height $\times$ width $\left(\mathrm{cm}^{2}\right)$ & $3.6 \times 3.6$ \\
\hline
\end{tabular}


The predicted distributions of gas-dynamic and electrical parameters along the channel are shown in figure 7 for the Hall current neutralized condition. These calculations indicate a total velocity increase of 150 percent with only a minor rise in static temperature. The static pressure at the end of the accelerator is $\approx 0.3 \mathrm{~atm}$, which is sufficient for further expansion to the 0.05 -atm backpressure limit of the test section. The current density and axial electric field are somewhat beyond the standard values accepted for reliable operation of MHD generators, but accelerators are far more energetically stressed in general and the expected lifetime for many applications of interest can be measure in minutes rather than hours of operation. Accelerator design and performance characteristics are summarized in table 5.

Table 5. MAPX performance characteristics.

\begin{tabular}{|c|c|}
\hline Seed (\% NaK) & 1 \\
\hline Applied magnetic field (tesla) & 2 \\
\hline Flow rate $(g / s)$ & 130 \\
\hline Inlet $P_{0}$ (atm) & 8.8 \\
\hline Inlet $P$ (atm) & 3.2 \\
\hline Inlet $T(\mathrm{~K})$ & 2,700 \\
\hline Inlet $M$ & 1.35 \\
\hline Inlet $u(\mathrm{~m} / \mathrm{s})$ & 1,300 \\
\hline Exit $P_{0}$ (atm) & 38.5 \\
\hline Exit $P$ (atm) & 0.28 \\
\hline Exit $T(\mathrm{~K})$ & 3,000 \\
\hline Exit $M$ & 3.52 \\
\hline Exit $u(\mathrm{~m} / \mathrm{s})$ & 3,550 \\
\hline Applied current (amps) & 300 \\
\hline Applied voltage (volts) & 4,400 \\
\hline Applied electrical power (MW) & 1.3 \\
\hline Power density $\left(\mathrm{GW} / \mathrm{m}^{3}\right)$ & 2.2 \\
\hline$\eta(\%)$ & 61 \\
\hline$\Delta$ & 0.28 \\
\hline Interaction parameter & 1.34 \\
\hline Enthalpy addition ratio & 2.5 \\
\hline MHD push work (kW) & 660 \\
\hline Total joule dissipation (kW) & 330 \\
\hline Wall heat flux $\left(W / \mathrm{cm}^{2}\right)$ & 890 \\
\hline$\varphi=E_{y} / E_{x}$ (effective value) & 1.8 \\
\hline
\end{tabular}

\subsubsection{Engineering Design}

Development of any MHD accelerator poses significant engineering design challenges. The problems are more severe with an MHD accelerator in comparison to an MHD generator because the stagnation enthalpy becomes several times larger as the flow is accelerated and because the sustained current densities must be substantially higher to obtain the desired performance. Thus, the accelerator environment is more energetically stressed due to increased thermal loading and erosive effects.

This difficulty is amplified by the so-called "velocity overshoot" phenomena. The increased stagnation temperature associated with accelerators yields high recovery temperatures and tends to drive the maximum temperature down into the boundary layer. The action of Joule heating in the concentrated 
current regions near the electrode elevates the boundary layer temperature even further. As a result, the boundary later becomes more highly conductive than the core flow, and the low density regions near the walls is Lorentz accelerated to a velocity higher than the core flow.

Electrical breakdown and development of microarcs at the electrode surface can also lead to major difficulties. Because the characteristic current carried by an arc is limited (5-10 A), the number of microarcs formed tends to increase in proportion to the electrode current. Consequently, erosive effects are enhanced and one must be further concerned about the propagation of microarcs downstream and the shorting of electrodes.

In this severe thermal environment, designers typically rely on water-cooled $\mathrm{Cu}$ alloy electrodes and $\mathrm{BN}$ insulators. Insulators formed by sputtering beryllium oxide onto a cooled metal structure are also common since they are known to provide good performance and durability. The principal constraints on mechanical design are related to magnet bore size and Lorentz force loading on the wiring harness.

Because short run times $(\approx 1 \mathrm{~s})$ were acceptable, it was decided to construct the MAPX accelerator as an expendable heat-sink device. The goal was to achieve a design that was simple and inexpensive to build yet durable enough to support several test runs before requiring refurbishment. The resulting construction detail is illustrated in the channel cross section shown in figure 8.

The basic concept is a channel lined with refractory materials, alumina for the insulating sidewalls and graphite for the electrode walls. These refractory materials are encased in a G-11 phenolic fiberglassreinforced box structure, which seals the duct and provides structural support. The principal thermal constraint for this design approach is an upper limit of $350^{\circ} \mathrm{F}$ for the $\mathrm{G}-11$ material. If the service temperature of the G-11 material is exceeded, the material will soften and is subject to the formation of gas voids and delamination.

The channel inner bore dictates an insulating wall thickness of less than 1 in. A wall construction comprised of 1/2-in alumina and 3/8-in-thick G-11 was therefore selected. The alumina has a low value of thermal conductivity and, upon exposure to the hot plasma stream, will experience a rapid rise in surface temperature. As the surface temperature rises, the heat transfer to the wall decreases.

The heat transferred to the surface during a test run will be trapped in the material when the run is terminated. Even though the conductivity of the material is low, the trapped heat will eventually dissipate throughout the material. Therefore, the backface temperature, which is in contact with the $\mathrm{G}-11$ outer structure, will continue to rise until it peaks 3-5 min following completion of a test run.

The use of a cooling purge through the channel before and after an accelerator firing has been implemented into the design with gas injector ports designed into the upstream flange. However, this purge will have only a limited cooling effect. Although heat transfer will decrease along the duct, the thickness of the alumina blocks is held constant along the total length of the sidewalls for simplicity of constructional maintenance.

In general, the electrode walls will be exposed to the same thermal flux as the insulator walls. There are no geometric constraints on the height of the electrodes, but the same temperature limitation applies at 
the interface between the electrode and G-11. Because the graphite has different properties than the alumina, principally a higher thermal conductivity, it should be much thicker than the alumina. On the other hand, it should not be overly thick, as this offers no advantage. For our design, the soak-out temperature was required to be less than that of the $1 / 2$-in-thick alumina sidewall at the same heating condition.

The graphite is also expected to erode in the oxygen-carrying plasma and form gaseous carbon dioxide and carbon monoxide. While this chemical erosion is an exothermic reaction, it is anticipated that the heat transfer will not be significantly increased. The cumulative erosion loss will be more pronounced at the entrance but is not expected to be a significant enough to warrant surface coating of the graphite.

The electrodes and alumina insulators are keystone-shaped pieces that are locked into position by the alumina sidewall blocks. The sidewall pieces are flat slabs of alumina with a lap joint in the axial segmentation. Once installed in the outer G-11 structure the refractory material can be floating, meaning that no rigid attachment to the outer walls is required. Axial motion is prevented by attachment of a channel exit flange. Diagonal shorting of the electrodes is accomplished by running short leads of wire between the external channel assembly and the magnet pole cap.

The fully assembled accelerator channel is shown schematically in figure 9 . The engineering drawings for this entire assembly have been completed, reviewed, and released to CoorsTec for fabrication.

\subsection{Secondary Nozzle and Test Section}

Additional exhaust velocity can be obtained by expanding the residual pressure at the end of the accelerator, the ultimate expansion being determined by the backpressure of the evacuation system. In the MAPX design, this is accomplished with a diverging duct.

In general, nonequilibrium flow prevails in the secondary nozzle, but previous work by Professor V.I. Alferov at TsAGI indicates that the secondary nozzle can be predicted reasonably well using a frozen flow model with $\gamma$ dependent on the species concentrations exiting the accelerator ${ }^{24}$ More detailed studies by Professor Alferov have shown that the presence of seed tends to deactivate the vibrational degrees of freedom for nitrogen, which can lead to an increase in velocity and a rise in static temperature at the nozzle exit. ${ }^{33}$

The secondary nozzle for MAPX is designed as an uncooled two-piece unit, which allows the flow train to be separated at a convenient location for maintenance purposes. The first stage section is $20 \mathrm{~cm}$ long with a $0.6^{\circ}$ divergence. Two interchangeable $32.5-\mathrm{cm}$-long secondary stage sections were designed having divergence angles of $1.7^{\circ}$ and $2.5^{\circ}$, respectively. These nozzles consist of plasma-sprayed carbon steel sheets welded together to form an expanding duct. The secondary nozzles were sized to exhaust into a large test section, which is evacuated by a nitrogen-driven ejector pump with a deadhead backpressure $<0.05 \mathrm{~atm}$. The secondary nozzles, test section, and ejector pump were all custom fabricated in MSFC facilities. 


\section{MEASUREMENTS AND DIAGNOSTICS}

The principal parameters governing accelerator operation and performance are the electrical characteristics measured at the power terminals and at the channel electrodes. During MAPX operation, individual electrodes will float as high as $8-10 \mathrm{kV}$ with respect to ground whereas interelectrode potentials will be less than $100 \mathrm{~V}$. This high, common-mode voltage environment requires special precaution with respect to electrical isolation and selection of transducers. As a minimum, electrical characteristics will be measured on at least half of the channel electrodes at initial startup of the facility, and this number will be expanded to provide complete channel monitoring capability as research proceeds. In the long term, wire probes will be incorporated to examine potential distributions within the plasma.

Other facility parameters to be monitored in real time include cooling water pressures and flow rates for the various subsystems as well as thermocouple readings at selected locations along the flow train. The arc heater, electromagnet systems, and MHD accelerator each have independent control and monitoring systems. Therefore, conduct of tests will depend on preplanned coordination of all three facility control systems.

The plasma parameter of central importance to accelerator performance is the electrical conductivity. To address this concern, a newly acquired polychromatic quadrature microwave interferometer to interrogate the plasma at both the entrance and exit of the accelerator will be utilized. This device, shown schematically in figure 10 , simultaneously transmits and receives three frequencies $(70,90$, and $110 \mathrm{GHz})$, and can be operated in reflectometer mode. For further details, the reader is referred to some recently published experiments in which this device was successfully used on seeded combustion plasmas. ${ }^{34}$

The flow parameter of central importance with respect to accelerator performance is the velocity at the exit of the accelerator and the secondary nozzle. It is also desirable to determine the actual thermodynamic state of the flow at these same locations, since the static temperature will be indicative of the relative influence of electromagnetic versus electrothermal effects within the accelerator.

The simplest and probably crudest method of determining the effective velocity is to measure the induced potential between two unpowered electrodes at the end of the accelerator channel and compute the velocity from the simple relation $V=u B h$. This method is subject to large uncertainty because the boundary layer voltage drop conceals the true potential drop in the core flow. Nevertheless, this method is extremely useful and instructive and will be implemented as part of the MAPX experiments.

Another crude but simple method that may prove useful is the cross correlation of signals obtained from closely spaced, fast-response optical detectors in the channel. This method could readily be implemented

using optical fibers and fast digital signal processing techniques to obtain time-of-flight estimates for natural or induced disturbances in the flow. 
A more accurate indicator of core velocity, which will be utilized, is the gas-dynamic method. Here, if the stagnation pressure is measured both with and without MHD effects at the same location, it can be shown through a profile similarity argument that

$$
\frac{P_{0, \mathrm{MHD}}}{P_{0}} \cong \frac{u_{\mathrm{MHD}}}{u}
$$

Ultimately, accurate measurements of velocity profiles across the channel demand use of sophisticated laser-based diagnostics. A logical candidate is planar laser-induced fluorescence (PLIF) of the sodium atom. For the conditions expected in MAPX, the sodium line width will be greater than the line width of the ND:YAG-pumped dye laser; thus, temperature and velocity can be measured by resolving the Doppler width (temperature) and shift due to bulk flow (velocity). The data are time-resolved by imaging the fluorescence through a Fabry-Perot interferometer and utilizing a gated intensified charged-coupled device (ICCD) camera to capture a single laser pulse, as shown in figure 11.

Although nonequilibrium effects make measurement of flow temperature problematic, initial efforts will rely on emission spectroscopy to deduce the vibrational temperature of various diatomic species. More extensive resolution of the multilevel kinetics must rely on diagnostics using laser stimulation.

Within the test section, the plan is to insert a wedge directly into the exhaust stream and obtain Schlieren images of the resulting shock angle. The low density of the flow makes the outcome questionable but the resulting data would be valuable as a means of estimating Mach number and obtaining an effective value for the static temperature. 


\section{CONCLUSIONS}

An experimental research facility has been designed for investigating the use of MHD cross-field accelerators as a possible thrust augmentation device for thermal propulsion systems. This facility consists of a $1.5-\mathrm{MW}_{\mathrm{e}}$ arc heater thermal source driving a 2-MW $\mathrm{MHD}$ accelerator. The accelerator channel is configured as an externally diagonalized segmented channel, which is inserted into an existing large-bore, 2-T electromagnet. A low-cost, heat-sink accelerator design was adopted suitable for short-duration research tests $(\approx 1 \mathrm{~s})$. Performance analyses indicate good performance potential (150-percent velocity augmentation) for this design, although additional performance could be obtained with additional power input. The arc heater, electromagnet, test section, and all necessary power supplies are existing hardware and are currently being integrated into the flow train. The engineering drawings for the water-cooled entrance flow-path assembly, including seed injector, mixing chamber, and primary nozzle, the accelerator channel, and the secondary nozzle have been reviewed, approved, and released for fabrication. Delivery of these final components is expected by fall of 2002. Initial shakedown testing will start upon complete assembly of the facility, and an indepth research program will be initiated in an attempt to resolve the outstanding technical issues with respect to the intended application. 


\section{REFERENCES}

1. Wood, G.P.; and Carter, A.F.: "Considerations in the Design of a Steady DC Plasma Accelerator," Dynamics of Conducting Gases, Proceedings of the Third Biennial Gas Dynamics Symposium, A.B. Cambel and J.B. Fenn (eds.), Northwestern University Press, Evanston, IL, pp. 201-212, 1960.

2. Demetriades, S.T.; and Ziemer, R.W.: "Energy Transfer to Plasmas by Continuous Lorentz Forces," Magnetohydrodynamics, Proceedings of the Fourth Biennial Gas Dynamics Symposium, A.B. Cambel, T.P. Anderson, and M.M. Slawsky (eds.), Northwestern University Press, Evanston, Illinois, pp. 185205, 1962.

3. Demetriades S.T.; Hamilton, G.L.; Ziemer, R.W.; and Lenn, P.D.: "Three-Fluid Nonequilibrium Plasma Accelerators (Part I)," AIAA Progress in Astronautics and Aeronautics: Electric Propulsion Development, E. Stuhlinger (ed.), Academic Press, Inc., New York, Vol. 9, pp. 461-511, 1963.

4. Lenn, P.D.; Bodoia, J.R.; Ward, D.L.; Hamilton, G.L.; and Demetriades, S.T.: "Three-Fluid Nonequilibrium Plasma Accelerators (Part II)," AIAA 63-047, March 1963.

5. Blackman, V.H.; and Sunderland, R.J.: "Experimental Performance of a Cross-Field Plasma Accelerator," AIAA J., Vol. 1, pp. 2047-2052, 1963.

6. Demetriades, S.T.: "Momentum Transfer to Plasmas by Lorentz Forces," Physico-Chemical Diagnostics of Plasmas, Proceedings of the Fifth Biennial Gas Dynamics Symposium, T.PAnderson, R.W. Springer, and R.C. Warder (eds.), Northwestern University Press, Evanston, Illinois, pp. 297-328, 1964.

7. Sunderland, R.J.; and Asam, A.R.: "Magnetogasdynamic Rocket for Space Propulsion," NASA Contractor Report CR-54040, National Aeronautics and Space Administration, May 1964.

8. Ring, L.E.: "General Considerations of MHD Acceleration for Aerodynamic Testing," in Arc Heaters and MHD Accelerators for Aerodynamic Purposes, AGARDograph 84: Supplemental Volume, Proceedings of AGARD Specialists Meeting, North Atlantic Treaty Organization, Advisory Group for Aeronautical Research and Development, pp. 1-55, September 1964.

9. Wood, G.P.; Carter, A.F.; Sabol, A.P; McFarland D.R.; and Weaver, W.R.: "Research on Linear CrossedField Steady-Flow D.C. Plasma Accelerators at Langley Research Center, NASA," Arc Heaters and MHD Accelerators for Aerodynamic Purposes, AGARDograph 84: Part I, Proceedings of AGARD Specialists Meeting, North Atlantic Treaty Organization, Advisory Group for Aeronautical Research and Development, pp. 1-45, September 1964.

10. Carter, A.F.; Wood, G.P.; Sabol, A.P.; and Weinstein, R.H.: "Experiments in Steady-State High Density Plasma Acceleration," Proceedings of Third Symposium on Engineering Aspects of 
Magnetohydrodynamics (SEAM), C. Mannal and N.W. Mather (eds.), Columbia University Press, New York, pp. 45-55, 1962.

11. Wood, G.P.; Carter, A.F.; Sabol, A.P.; and Weinstein, R.H.: "Experiments in Steady-State Cross-Field Acceleration of Plasma," Physics of Fluids, Vol. 4, No. 5, pp. 652-652, May 1961.

12. Carter, A.F.; Wood, G.P.; McFarland, D.R.; and Weaver, W.R.: "Research on a Linear Direct-Current Plasma Accelerator," AIAA J., Vol. 3, No. 6, pp. 1040-1045, June 1965; AIAA 64-699, AugustSeptember 1964.

13. Carter, A.F.; McFarland, D.R.; Weaver, W.R.; Park, S.K.; and Wood, G.P.: "Operating Characteristics, Velocity and Pitot Distribution, and Material Evaluation Tests in the Langley One-Inch Square Plasma Accelerator," AIAA 66-180, March 1966.

14. Weaver, W.R.; McFarland, D.R.; Carter, A.F.; and Wood, G.P.: "Design and Operational Characteristics of the Langley 20-Megawatt Plasma Accelerator Facility," Proceedings of 11th Symposium on Engineering Aspects of Magnetohydrodynamics (SEAM), California Institute of Technology, Pasadena, CA, pp. 77-81, March 1970.

15. Carter, A.F.; Weaver, W.R.; McFarland, D.R.; Park, S.K.; and Wood, G.P.: "Design of the 20-Megawatt Linear Plasma Accelerator Facility," NASA TN D-6115, National Aeronautics and Space Administration, January 1971.

16. Whitehead, G.L.; MacDermott, W.N.; Siler, L.G.; and Roepke, R.G.: "Assessment of MHD Applications to Hypersonic Propulsion Testing Facilities," AEDC-TMR-87-V54, USAF Arnold Engineering Development Center, December 1984.

17. Rittenhouse, L.E.; Pigott, J.C.; Whoric, J.M.; and Wilson, D.R.: "Theoretical and Experimental Results with a Linear Magnetohydrodynamic Accelerator Operated in the Hall Current Neutralized Mode," $A E D C-T R-67-150$, USAF Arnold Engineering Development Center, November 1967.

18. Rittenhouse, L.E.; Whoric, J.M.; and Pigott, J.C.: "Experimental Results with a Linear Magnetohydrodynamic Accelerator Operated with Water-Cooled Beryllia Magnetic Field Walls," AEDC-TR-70-40, USAF Arnold Engineering Development Center, April 1970.

19. Teno, J.; Brogan, T.R.; and Petty, S.W.: "Research Studies and the Development of MHD Generators and Accelerators," AEDC-TR-70-14, USAF Arnold Engineering Development Center, January 1970.

20. Brogan, T.R.: "The 20MW LORHO MHD Accelerator for Wind Tunnel Drive: Design, Construction, and Critique," AIAA 99-3720, 1999.

21. Pate, S.R.; Siler, L.G.; Stallings, D.W.; and Wagner, D.A.: "Development of an MHD-Augmented, High Enthalpy, Shock Tunnel Facility," AIAA J., Vol. 12, No. 3, pp. 289-297, March 1974; AIAA 72-993, September 1972. 
22. Grabowsky, W.R.; Durran, D.A.; and Mirels, H.: "Performance of a 500-kjoule MHD Wind Tunnel," AIAA J., Vol. 7, No. 10, pp. 1846-1852, October 1969.

23. Harris, C. J.; Marston, C. H.; and Warren, W.R., Jr.: "MHD Augmented Shock Tunnel Experiments with Unseeded, High Density Air Flows," AIAA J., Vol. 13, No. 2, pp. 229-231, February 1975.

24. Alferov, V.I.: "Current Status and Potentialities of Wind Tunnels with MHD Acceleration," High Temperature, Vol. 38, No. 2, pp. 300-313, 2000.

25. Gordon, S.; and McBride, B.J.: "Compute Program for Calculation of Complex Chemical Equilibrium Compositions, Rocket Performance, Incident and Reflected Shocks, and Chapman-Jouguet Detonations," NASA SP-273, National Aeronautics and Space Administration, 1971.

26. Frost, L.S.: "Conductivity of Seeded Atmospheric Pressure Plasma," J. App. Phys., Vol. 32, No. 10, pp. 2029-2039, 1961.

27. De Montardy, A.: “MHD Generator with Series-Connected Electrodes," Proceedings of the International Symposium on MHD Electrical Power Generation, Newcastle upon Tyne, England, Paper No. 19 , September 1962.

28. Dicks, J.B.: "Design and Operation of Open Cycle Hall Current Neutralized MHD Accelerators and Generators with Diagonal Conducting Strip Walls," Proceedings of Fifth Symposium on Engineering Aspects of Magnetohydrodynamics (SEAM), Massachusetts Institute of Technology, Cambridge, MA, April 1964.

29. Dicks, J.B.: "Improvements in Design of MHD Accelerator Channels for Aerodynamic Purposes," Arc Heaters and MHD Accelerators for Aerodynamic Purposes, AGARDograph 84: Supplemental Volume, Proceedings of AGARD Specialists Meeting, North Atlantic Treaty Organization, Advisory Group for Aeronautical Research and Development, pp. 127-174, September 1964.

30. Wu, Y.C.L.: "Performance Theory of Diagonal Conducting Wall MHD Generators," AIAA J., Vol. 14, No. 10, pp. 1362-1368, October 1976.

31. Powers, W.L.; Dicks, J.B.; and Snyder, W.T.: "A Graphical Presentation of MHD Accelerator and Generator Performance Characteristics," AIAA J., Vol. 5, No. 12, pp. 2232-2236, December 1967.

32. Rosa, R.J.: "Hall and Ion Slip Effects in a Nonuniform Gas," Phys. Fluids, Vol. 5, No. 9, pp. 10811090, September 1962.

33. Alferov, V.I.; Dmitriev, L.M.; Yegrov, B.V.; and Markachev, Y.E.: "Investigation of Physico-Chemical Processes in Hypervelocity MHD Gas Acceleration Wind Tunnels," Proceedings of 33d Symposium on Engineering Aspects of Magnetohydrodynamics (SEAM), The University of Tennessee Space Institute, Tullahoma, TN, pp. V.1-1 to V.1-7, June 1995.

34. Litchford, R.J.; Jones, J.E.; Dobson, C.C.; Cole, J.W.; Thompson, B.R.; Plemmons, D.H.; and Turner, M.W.: "Pulse Detonation Rocket MHD Power Experiment," AIAA 2002-2231, 2002. 


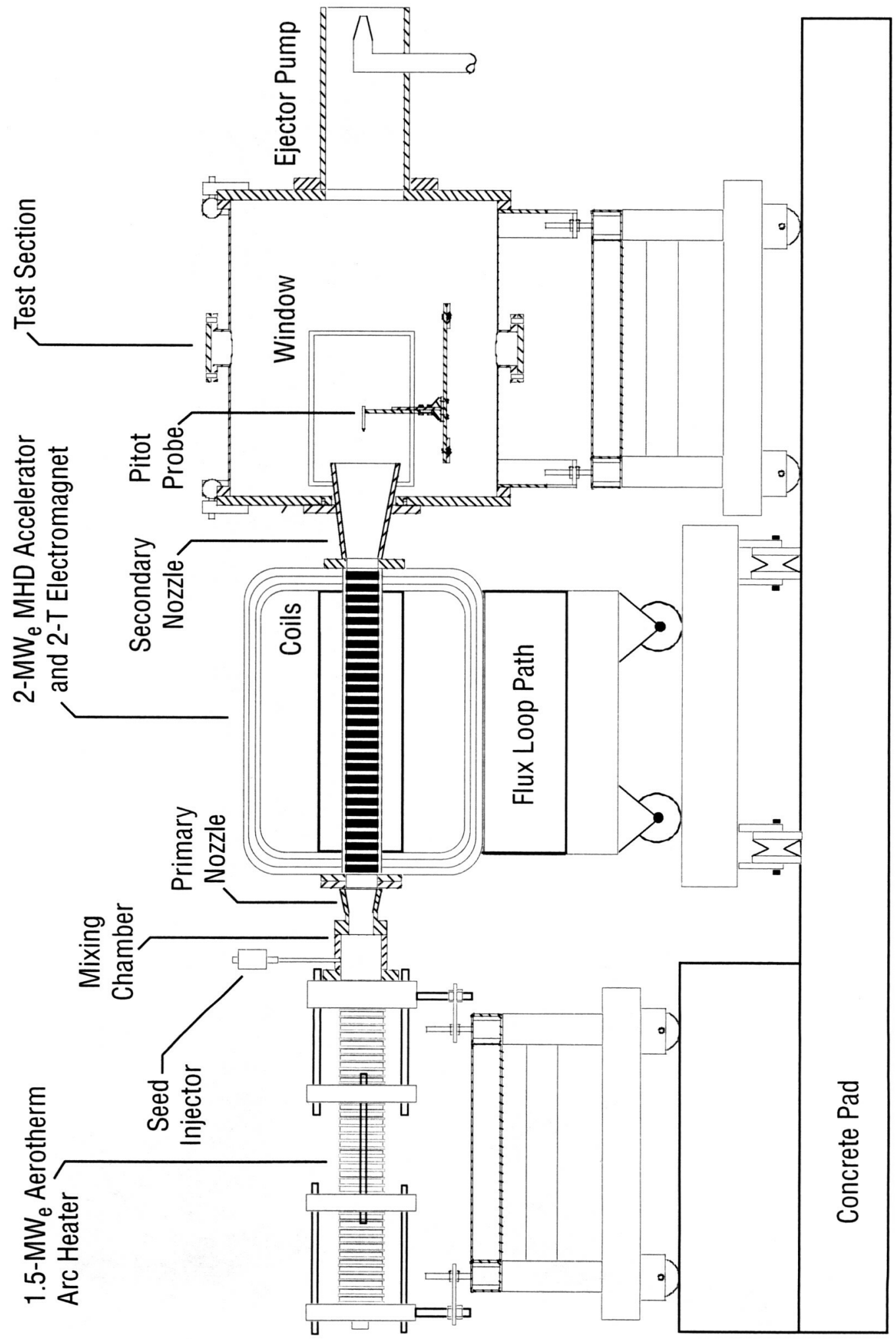

Figure 1. Schematic of NASA MSFC's MAPX facility. The major flow-path components are: (1) 1.5- $\mathrm{MW}_{\mathrm{e}}$ Aerotherm arc heater, (2) seed injector and mixing chamber, (3) primary expansion nozzle, (4) 2-MW $\mathrm{MW}_{\mathrm{e}} \mathrm{MHD}$ accelerator channel and 2-T electromagnet, (5) secondary nozzle, (6) windowed test section, and (7) N-driven ejector pump. 

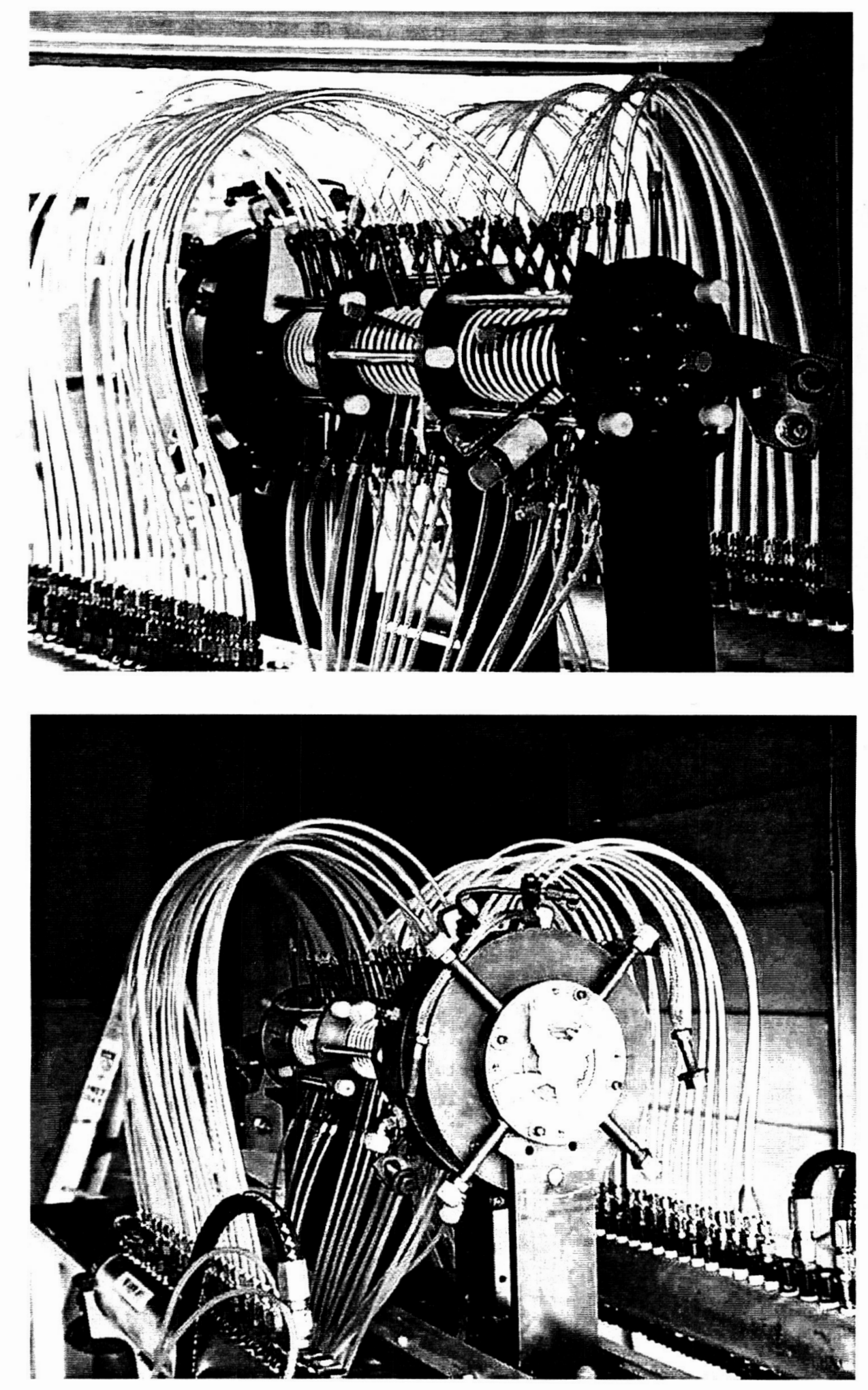

Figure 2. Photographs of the $1.5-\mathrm{MW}_{\mathrm{e}}$ Aerotherm arc heater in preparation for shakedown testing. 


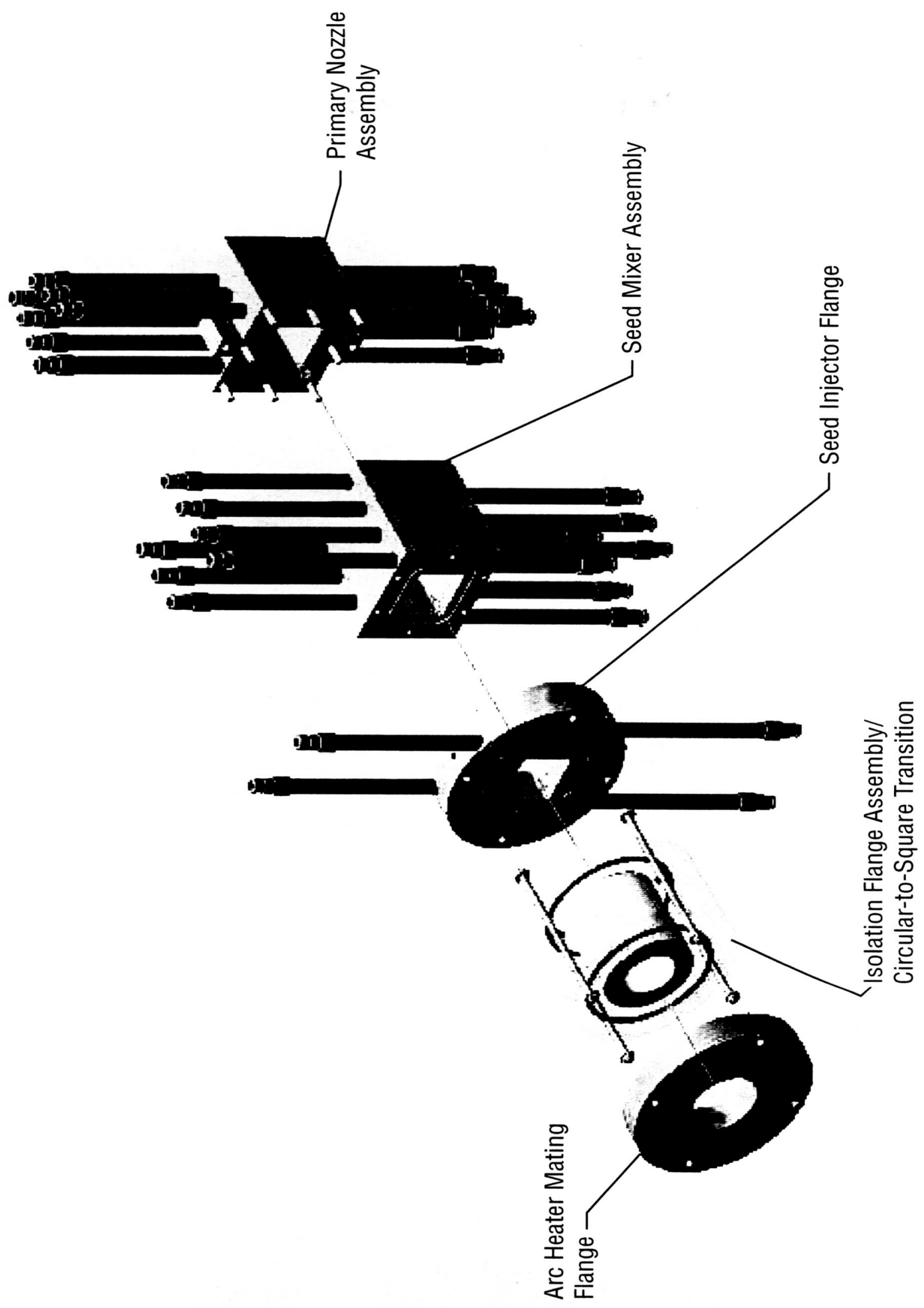

Figure 3. Exploded schematic of entrance flow-path assembly for MAPX. The major pieces include (1) the ceramic isolation flange, which electrically isolates the MHD accelerator from the arc heater and provides a circular-to-square cross-section transition; (2) the water-cooled seed-injector flange and mixer assembly; and (3) the water-cooled primary nozzle assembly. 

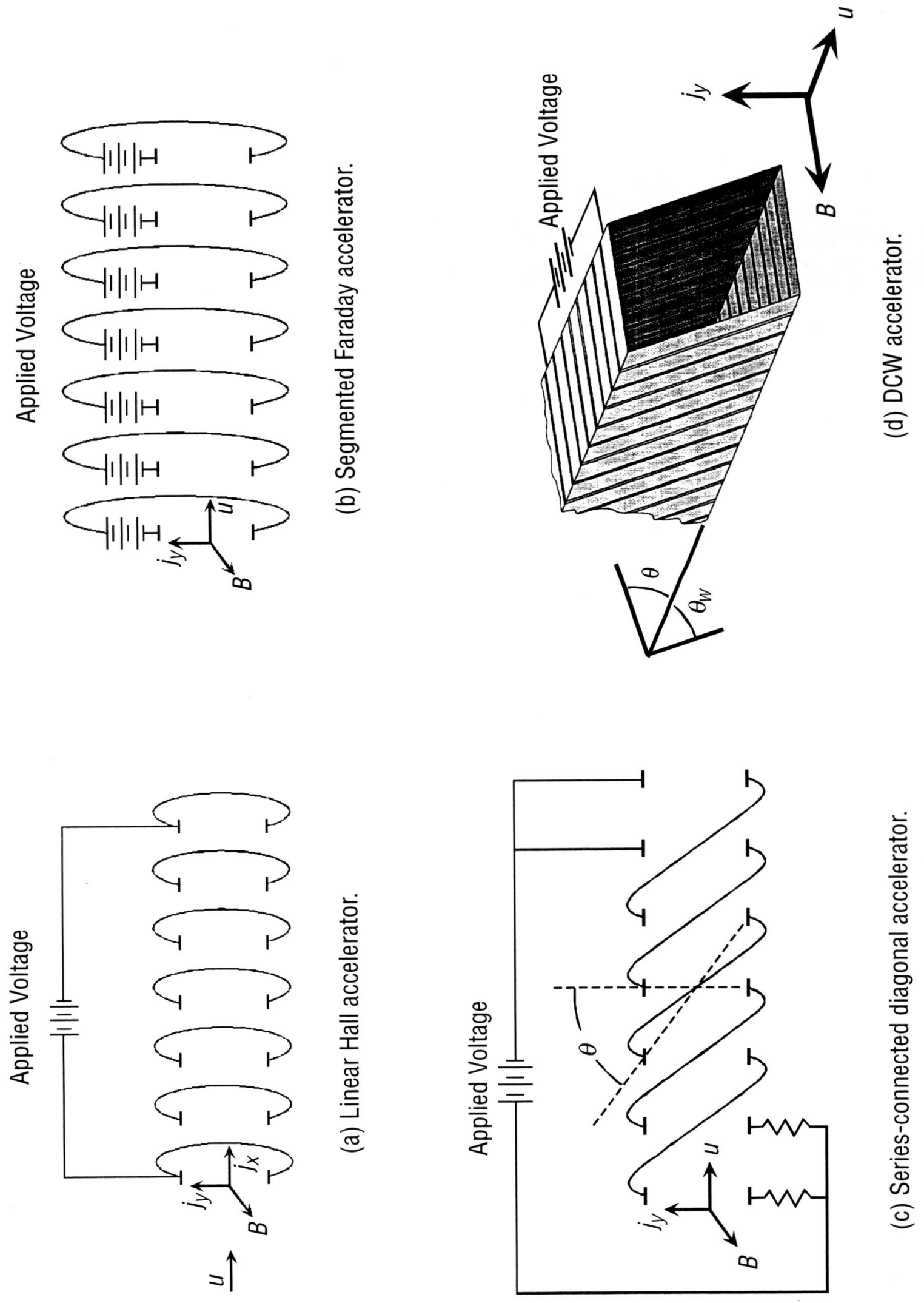

Figure 4. Alternative MHD accelerator configurations. 


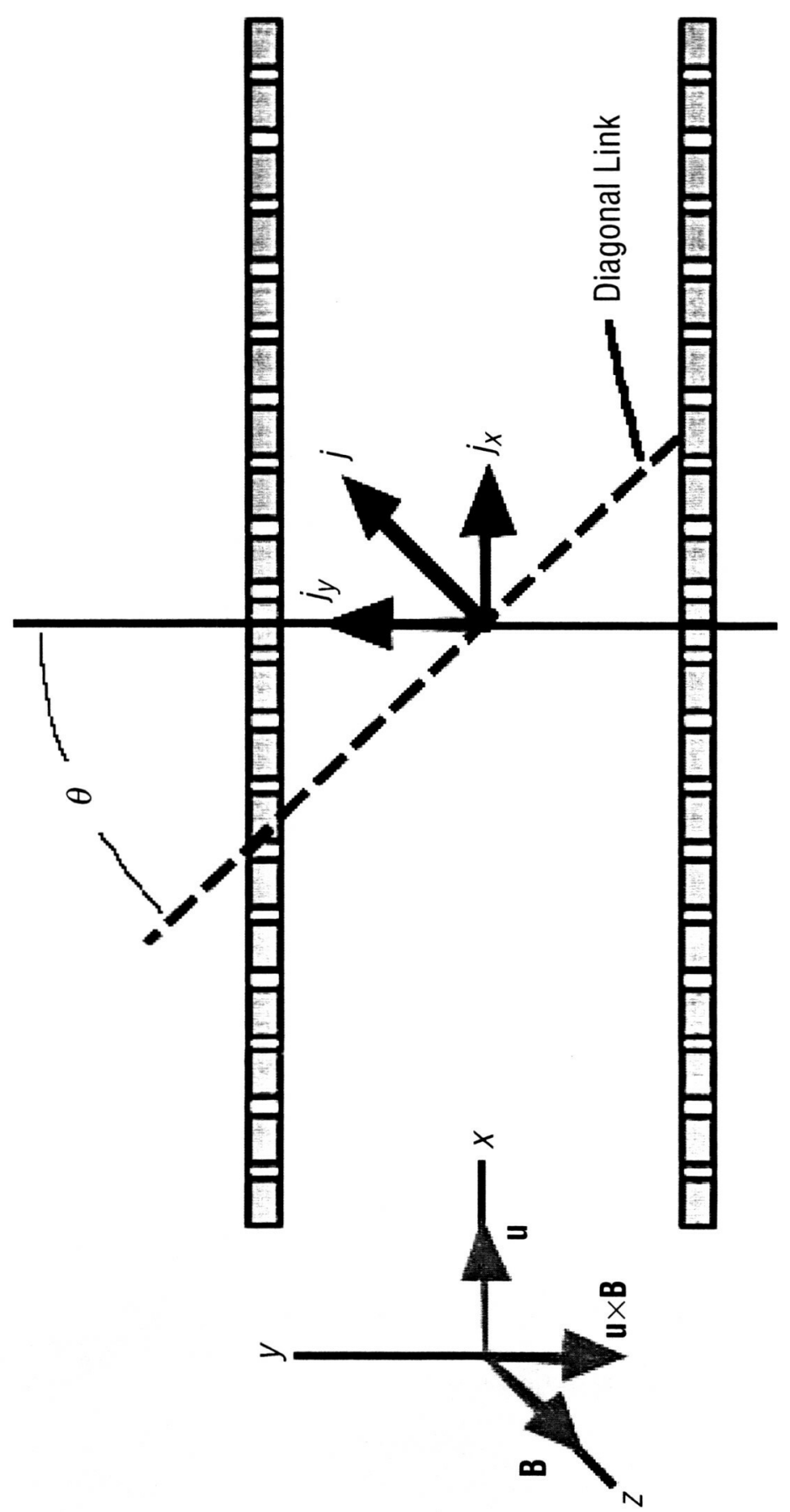

Figure 5. Illustration of diagonal linkage and the resulting field vector orientations. 


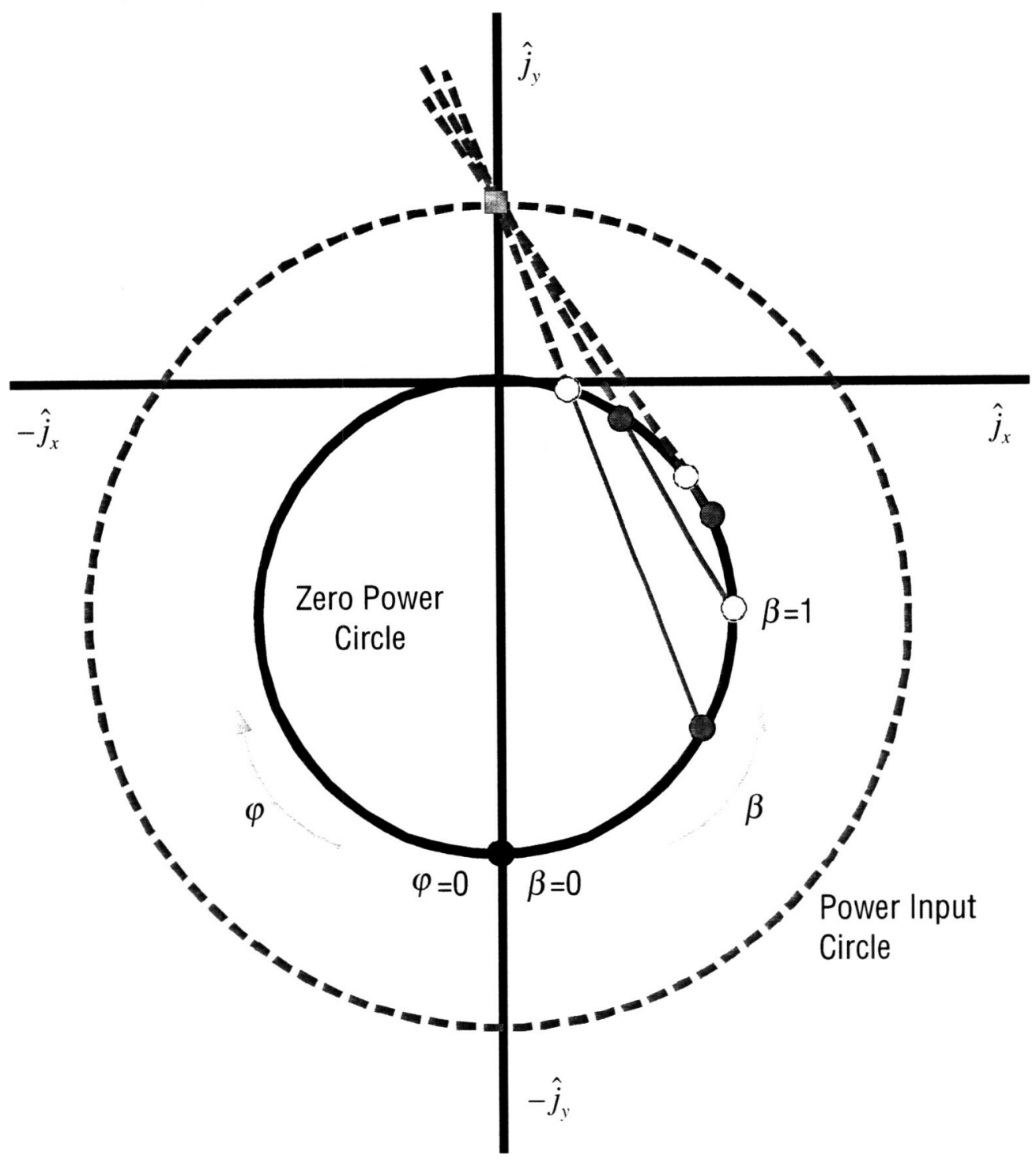

Diagonalization Angle $(\varphi)$

(O) Hall Parameter $(\beta)$

9 Hall Current Neutralized Condition

Figure 6. Performance diagram for Hall current neutralized accelerator. 

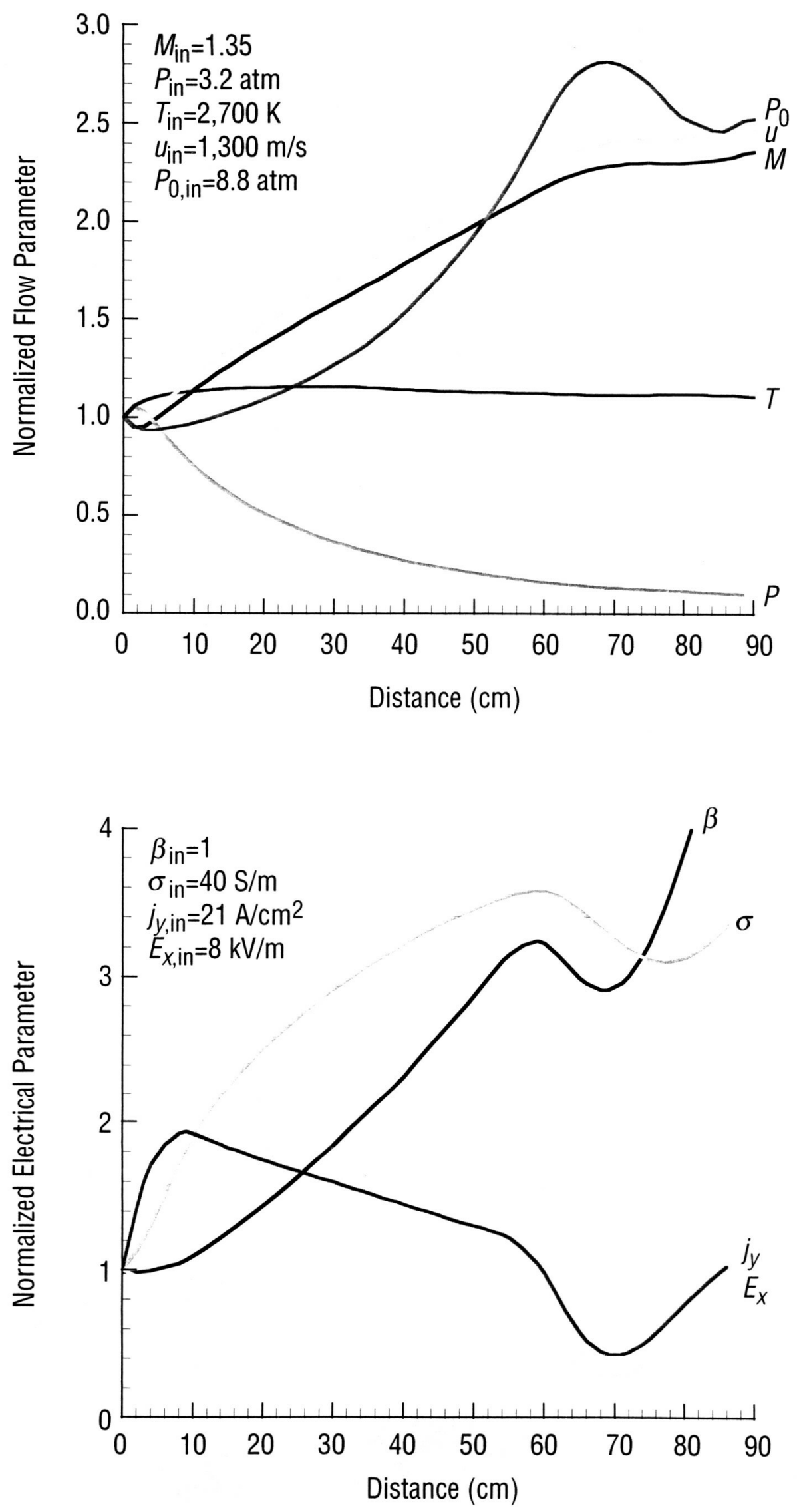

Figure 7. Predicted distributions of gas-dynamic and electrical properties along the channel of the MAPX accelerator for the Hall current neutralized condition. All parameters are normalized by their value at the inlet. 


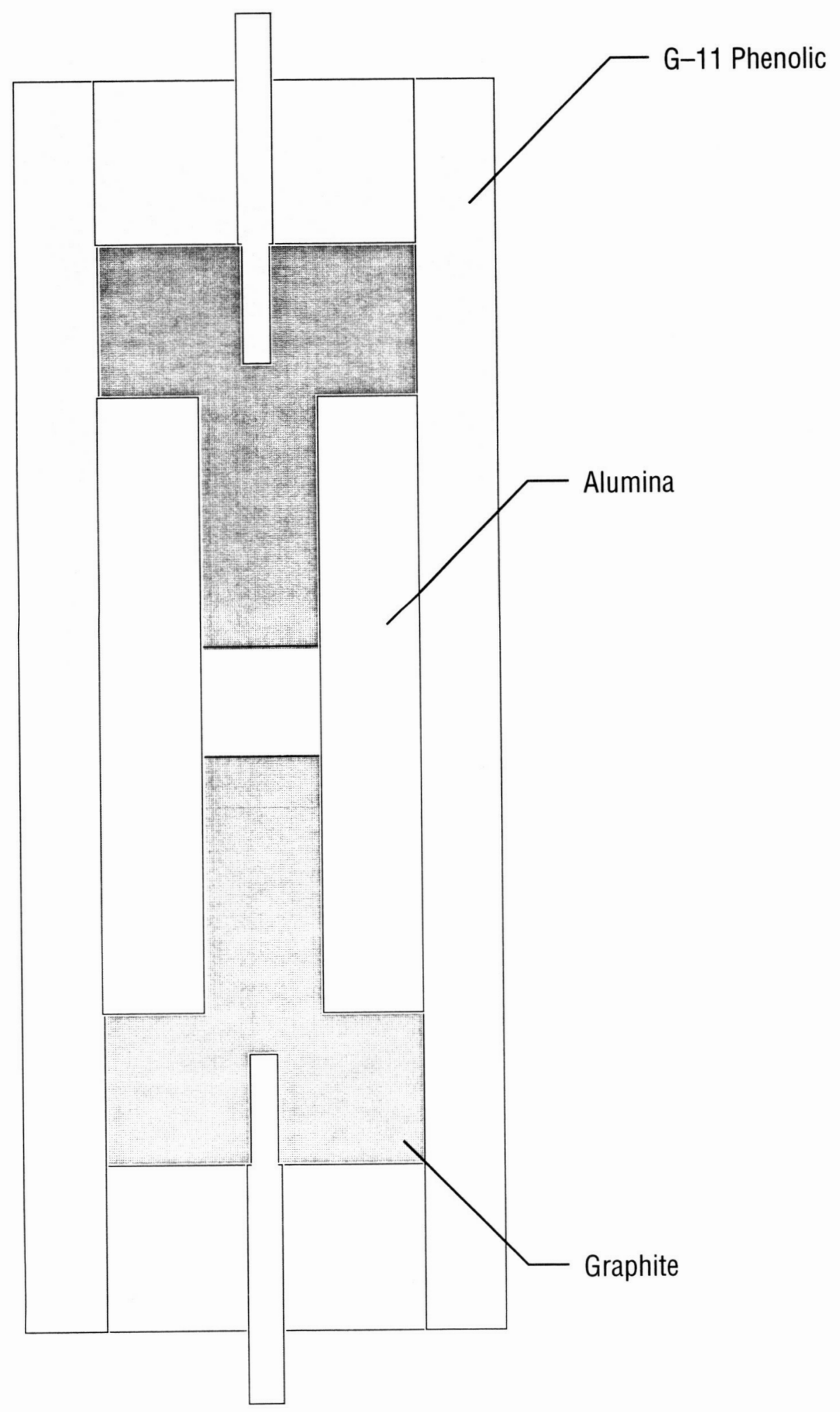

Figure 8. Cross section of heat-sink accelerator channel illustrating construction detail. 


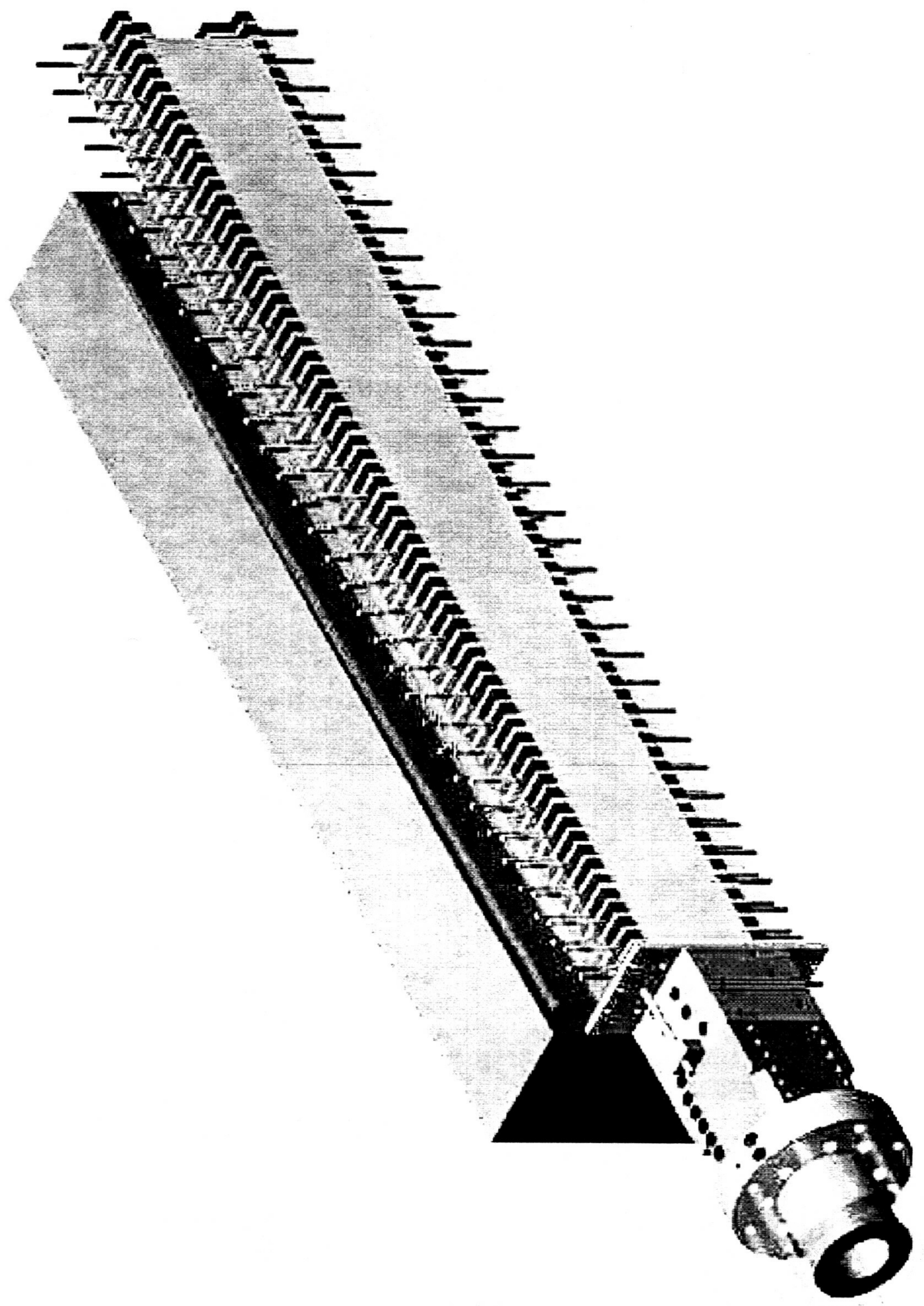

Figure 9. Schematic of fully assembled MAPX accelerator channel positioned inside the magnet bore.

31 


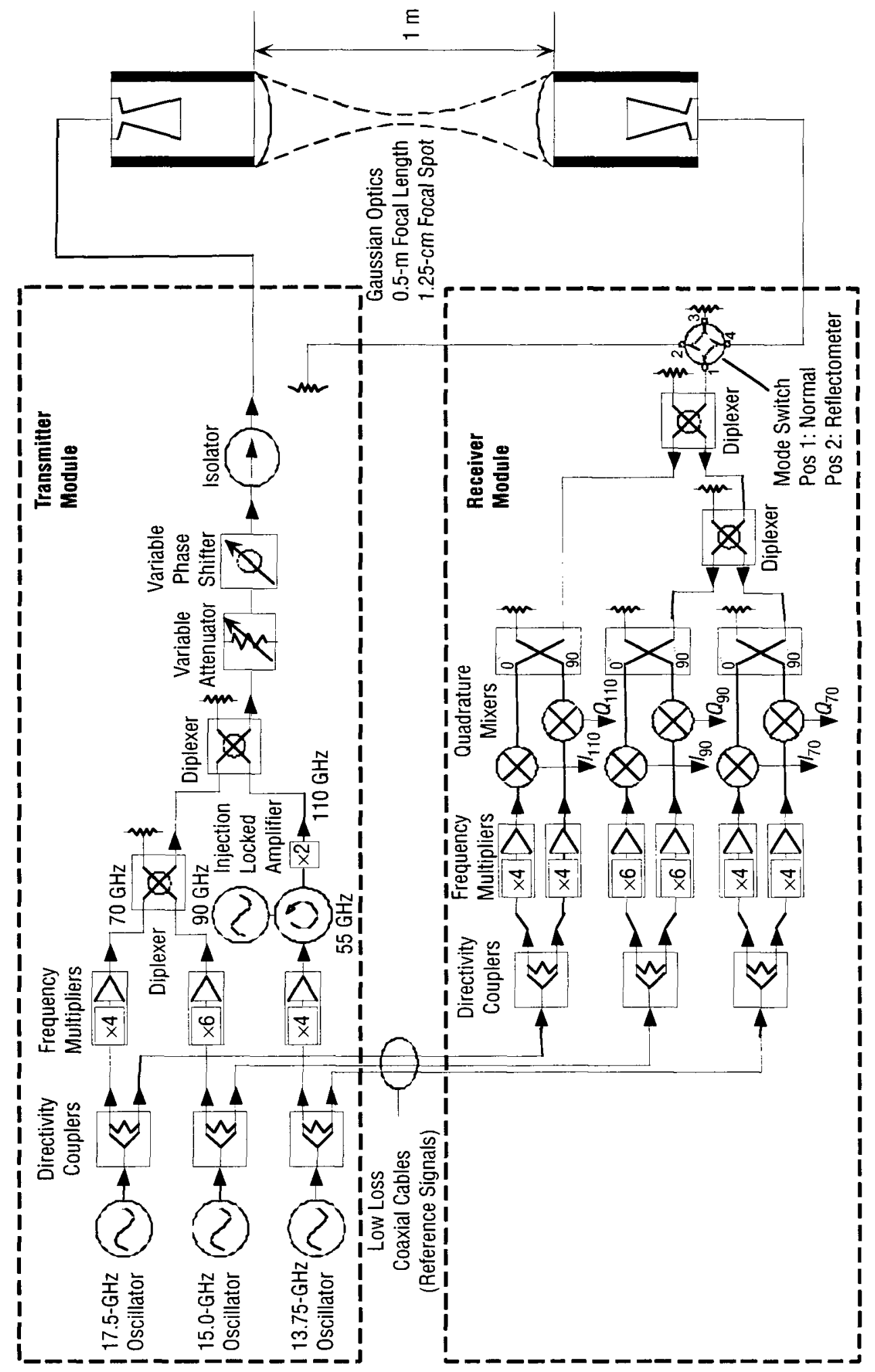

Figure 10. Schematic of microwave interferometer. It simultaneously probes at 70,90 , and $110 \mathrm{GHz}$ and may be operated in reflectometer mode. 


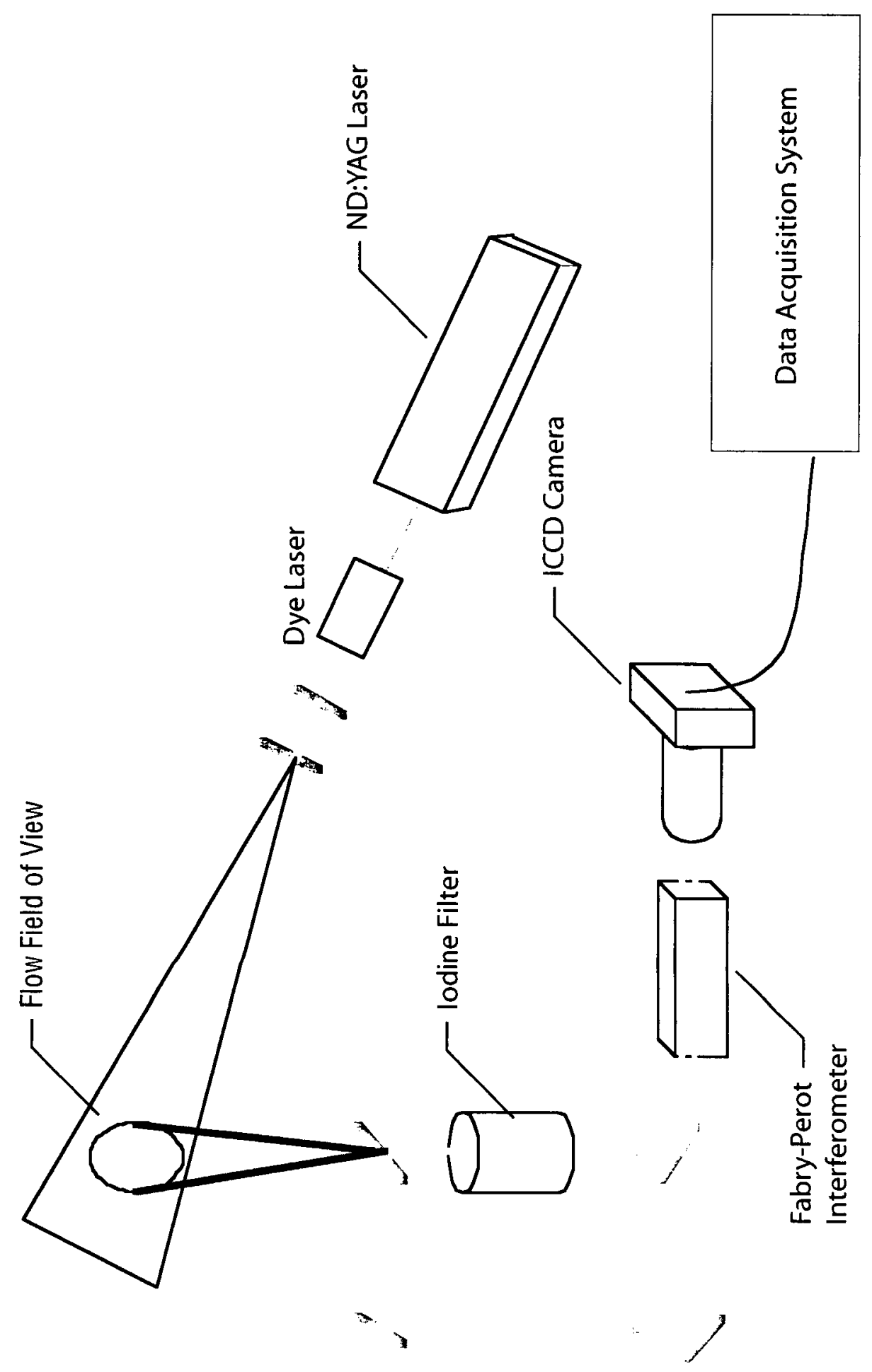

Figure 11. PLIF velocity/temperature diagnostic. 


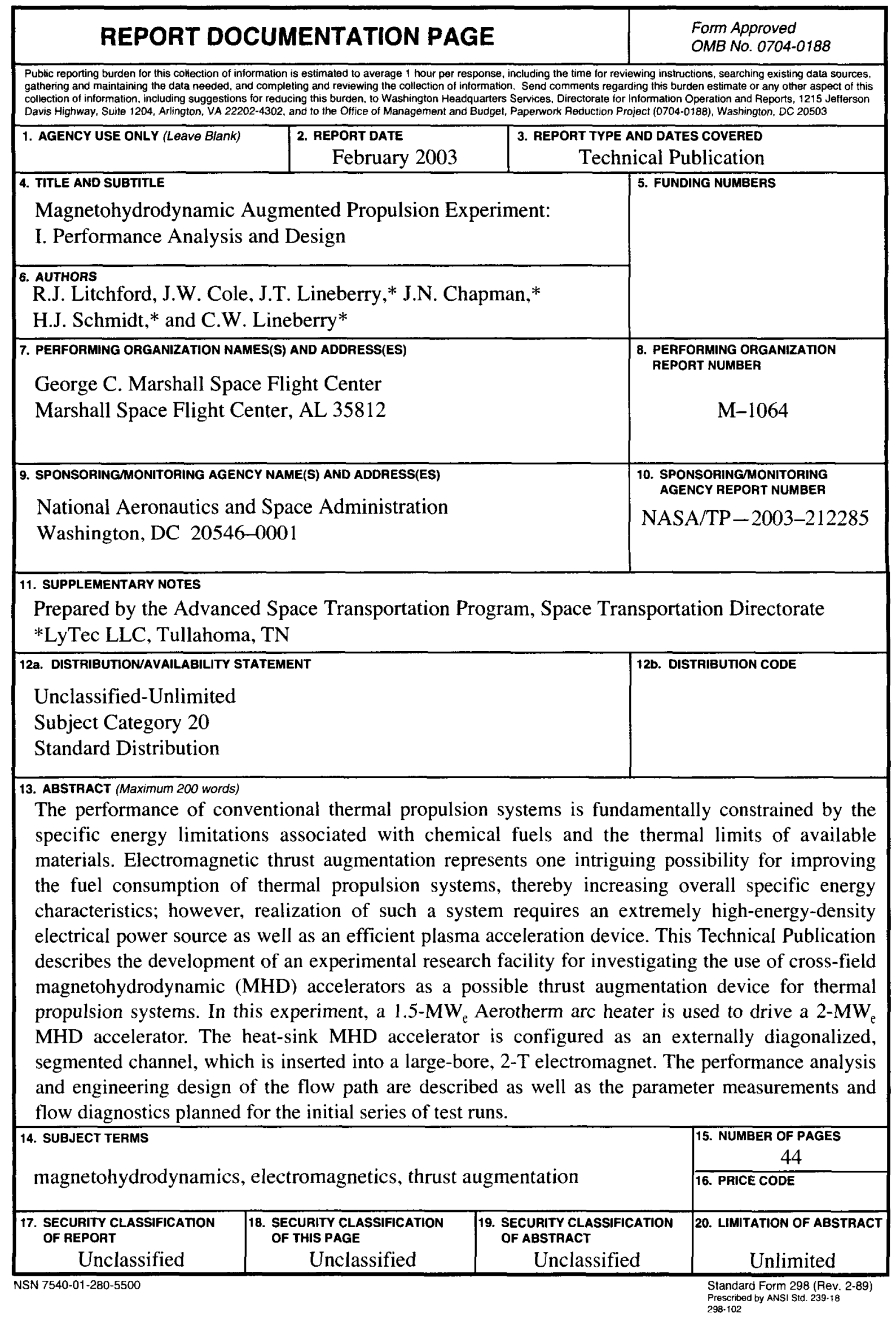

